\title{
Cyclotrimerization
}

\section{An Investigation into the Stephens-Castro Synthesis of Dehydrotriaryl[12]annulenes: Factors Influencing the Cyclotrimerization}

\author{
Paul N. W. Baxter, ${ }^{*[a]}$ Abdelaziz Al Ouahabi, ${ }^{[a]}{ }^{[}$Lydia Karmazin, ${ }^{[b]}$ Alexandre Varnek, ${ }^{[c]}$ \\ Jean-Marc Strub, ${ }^{[\mathrm{d}]}$ and Sarah Cianferani ${ }^{[\mathrm{d}]}$
}

Abstract: Detailed investigation into the CuX/base/phosphine modified Stephens-Castro syntheses of dehydrotriaryl[12]annulenes 1-3 have shown that cyclization is suppressed by excess CuX, strong donor ligands, high dilution conditions, and thermally unstable ethynylcuprate monomers. Surprisingly, intermediate dimer $\mathbf{1 6}$ plays only a minor role in the formation of $\mathbf{2}$ and 4. Overall, our findings are consistent with a cyclization pathway governed more by the nature of prior self-association of the ethynylcuprate monomers. Crystallographic characterization of tetrameric by-product $\mathbf{4}$, is also reported and revealed that it assembles into tubular stacks in the solid state.

\section{Introduction}

Dehydrotribenzo[12]annulene $^{[1]}$ ([12]DBA, 1, Scheme 1) has grown in popular recognition since its first reported syntheses in $1966,{ }^{[2-4]}$ to become a structural classic within the field of hydrocarbon and macrocyclic chemistry. ${ }^{[5-7]}$

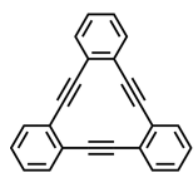

1
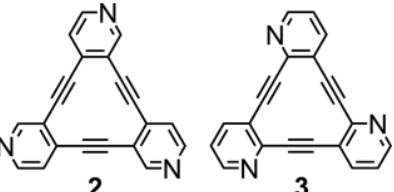

3
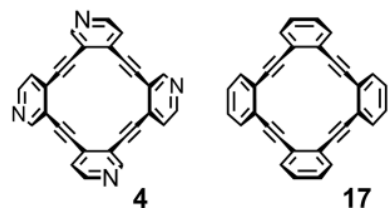

Scheme 1.

The interest stems from its unique triangular conjugated architecture, $^{[8,9]}$ and that it can be directly prepared via an

[a] Institut Charles Sadron, UPR 22 (CNRS-UdS)

23 rue du Loess, 67034 Strasbourg, France

E-mail: baxter@unistra.fr

http://www-ics.u-strasbg.fr

[b] Service de Radiocristallographie, Fédération de Chimie "Le Bel" FR2010, Tour de Chimie,

1 rue Blaise Pascal, 67008 Strasbourg, France

[c] Laboratoire de Chémoinformatique, UMR 7140 CNRS, Université de Strasbourg,

4 rue Blaise Pascal, 67000 Strasbourg, France

[d] Laboratoire de Spectrométrie de Masse Bio-Organique, Département des Sciences Analytiques IPHC, UMR 7178 (CNRS-UdS) ECPM, 25 rue Becquerel, 67087 Strasbourg, France

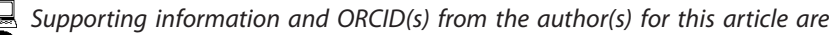
available on the WWW under https://doi.org/10.1002/ejoc.201901053. unusual Stephens-Castro-mediated cyclotrimerization reaction from 2-iodoarylethyne precursors (Scheme 2). ${ }^{[2,4,10,11]}$ It is also the smallest substructure of a potentially large class of multiply fused triangular [12]DBA hydrocarbons of increasing interconnectivity and crosslinking, leading ultimately to the polymer graphyne, a hypothetical expanded carbon network predicted to possess many intriguing mechanical and physicochemical properties. $^{[12-17]}$

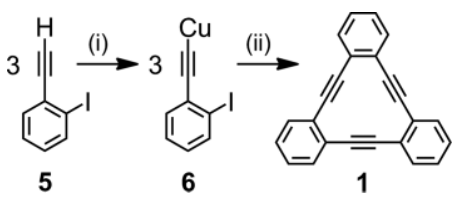

Scheme 2. Stephens-Castro cyclotrimerization synthesis of 1. (i) $\mathrm{CuSO}_{4} /$ $\mathrm{NH}_{2} \mathrm{OH} \cdot \mathrm{HCl}$ in $\mathrm{EtOH} / \mathrm{H}_{2} \mathrm{O}$; or $\mathrm{CuX}\left(\mathrm{X}=\mathrm{Cl}\right.$, I) and base (e.g. $\left.t \mathrm{BuOK}, \mathrm{K}_{2} \mathrm{CO}_{3}\right)$ in $\mathrm{N}$-donor solvents at ambient temperature; (ii) $\Delta\left(140-170{ }^{\circ} \mathrm{C}\right)$.

However, despite these considerations, 1 remained very much a laboratory curiosity until the mid-1980s when it was found to form metal sandwich complexes with potential molecular electronics applications. ${ }^{[18-20]}$ Motivated by renewed interest in carbon allotropes, multiply fused [12]DBAs were also prepared as model systems for the study of graphyne. ${ }^{[12,21-28]}$

In line with the novel conjugated structure of 1, [12]DBAs have since been found to function as new types of high spin magnetic, ${ }^{[4,29,30]} 2$-photon absorbers, ${ }^{[21,31]}$ liquid crystalline ${ }^{[32]}$ and vesicular materials, ${ }^{[33]}$ gels, $^{[34]}$ platforms for chiral recognition $^{[35]}$ and inclusion, ${ }^{[36]}$ as well as affording stacked charge transfer arrays, ${ }^{[37]}$ novel charge transport materials with potential for use as organic semiconductors, ${ }^{[21,34,38,39]}$ and porous networks which absorb $\mathrm{CO}_{2}$ gas. ${ }^{[40,41]}$

In accordance with the wide ranging interest and potential that [12]DBAs offer for materials science applications, an expanded range of synthetic methods have been developed for 
the construction of the [12]DBA ring system. However, the Stephens-Castro cyclotrimerization synthesis of $\mathbf{1}$ (Scheme 2) remained the preferred method for the syntheses of symmetrically trisubstituted [12]DBAs, ${ }^{[42-44]}$ until it was superseded by the adaptation of lyoda et al., ${ }^{[25]}$ using $\mathrm{K}_{2} \mathrm{CO}_{3} / \mathrm{Cul} / \mathrm{PPh}_{3}$ in DMF. $^{[36,37,39,45]}$ Sonogashira-Hagihara conditions ${ }^{[46,47]}$ have also been successfully utilized with sensitive substrates. ${ }^{[21,37,48,49]} \mathrm{Al}$ though of less general utility, ${ }^{[44]}$ the latter approach to [12]DBAs has been successfully demonstrated under phase transfer conditions, ${ }^{[26,35,50,51]}$ and in ionic liquids, ${ }^{[52]}$ as well as via the insitu generation of the 1-halo-2-ethynylbenzene. ${ }^{[53]}$ Ethyne metathesis cyclotrimerizations have also been successfully employed for [12]DBA syntheses, ${ }^{[54,55]}$ although this approach is restricted to symmetric [12]DBAs that do not have regiochemical issues.

Since the pioneering work of Staab et al., using Wittig methodology, ${ }^{[3,4]}$ various alternative intramolecular ring-closing strategies have also been employed using Sonogashira-Hagihara coupling, ${ }^{[28,32]}$ ethyne metathesis ${ }^{[21,23]}$ and aldehyde coupling approaches. $^{[22,24]}$ Miscellaneous syntheses of [12]DBAs via $[2+2+2]$ phenyl-ethyne cycloreversion ${ }^{[56]}$ and a 6-component one-pot cyclization with o-diiodobenzenes and acetylene gas, ${ }^{[57]}$ have also been reported, but have not so far found general usage.

Overall, the Stephens-Castro methodology as originally reported, ${ }^{[2]}$ still remains one of the most general and reliable methods of syntheses of regiosymmetric [12]DBAs. In view of the importance of this reaction, it is therefore rather surprising that comparatively little is understood about its mechanism, and how the substrate structure and reaction conditions influence the cyclotrimerization yield.

In the course of our studies on the generation of coordination networks with dehydrotripyridyl[12]annulene 2 (Scheme 1 and Scheme 3), progress was severely hampered by the low

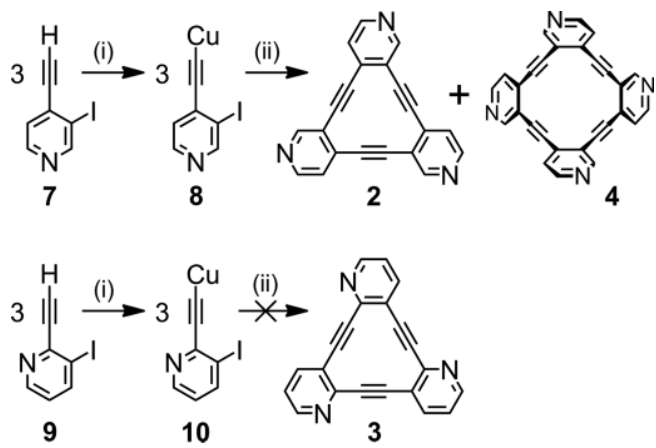

Scheme 3. Stephens-Castro mediated cyclizations to give $\mathbf{2}$ and $\mathbf{4}$, and attempted preparation of 3 . (i) $\mathrm{CuX}(\mathrm{X}=\mathrm{Cl}, \mathrm{I})$ and base (e.g. $\left.t \mathrm{BuOK}, \mathrm{K}_{2} \mathrm{CO}_{3}\right)$ in $\mathrm{N}$-donor solvents at ambient temperature; (ii) $\Delta\left(120-170{ }^{\circ} \mathrm{C}\right.$ ). cyclization yields using the procedure of Eglinton et al. ${ }^{[2]}$ We therefore carried out a detailed investigation into determining the factors necessary for optimizing the Stephens-Castro cyclotrimerization process and then applied the optimized conditions discovered for $\mathbf{2}$ to the attempted generation of isomeric dehydrotripyridyl[12]annulene $\mathbf{3}$, as well as an improved synthesis of the tribenzo system 1. In conjunction with this work, a reinvestigation into the catalytic modification of the StephensCastro mediated cyclotrimerization of $\mathbf{6}$ to $\mathbf{1}$ (Scheme 2) was also undertaken, in order to throw more light onto the possible mechanism of the cyclization process. Details of these studies and resulting conclusions are described below.

\section{Results and Discussion}

\section{Generation of 2 by Transition Metal Catalysis}

Our initial synthesis of $2^{[58]}$ utilized the classical StephensCastro reaction conditions described for the synthesis of $1,{ }^{[2,43]}$ whereby aqueous $\mathrm{NH}_{2} \mathrm{OH} \cdot \mathrm{HCl}$ reduction of $\mathrm{CuSO}_{4}$ in the presence of the 2-iodoarylethyne directly yields the ethynylcuprate, which is then heated in pyridine to effect the cyclotrimerization. However, this procedure only afforded 2 in low (5\%) yields. As palladium catalytic methods have been reported to be a successful alternative to the Stephens-Castro route for the preparation of [12]DBAs, ${ }^{[37]}$ we investigated this approach for the generation of 2 (Table 1, entries 1-3). However, with solvents and temperatures that are so generally successful for the Sonogashira-Hagihara coupling, these conditions were actually detrimental to the cyclization of $\mathbf{8}$, affording either zero or only very low yields of 2. Furthermore, application of the modified catalytic Stephens-Castro methodology as described by lyoda et al., ${ }^{[25]}$ yielded only a trace of $\mathbf{2}$ (entry 4, Table 1).

One possible reason why the catalytic experiments gave at best only poor yields of $\mathbf{2}$ may lie in the instability of the orthoiodoethynylpyridine $\mathbf{7}$ towards $\mathrm{N}$-donor solvents. The light sensitive 7 was found to undergo extensive decomposition to an as yet unidentified black material upon standing in deoxygenated N-donor solvents for a period of days to weeks. This process is accelerated by heating, and suggests that the decomposition-sequestration rate of $\mathbf{7}$ is more rapid than coupling under the experimental conditions investigated.

\section{Effect of [Cu'] on the CuX/tBuOK Mediated Stephens- Castro Cyclotrimerization of $\mathbf{8}$ to 2}

In contrast to the instability of $\mathbf{7}$ in $\mathrm{N}$-donor solvents, the ethynylcuprate $\mathbf{8}$ is indefinitely thermally stable under identical

Table 1. Attempted synthesis of $\mathbf{2}$ from $\mathbf{7}$ using catalytic conditions.

\begin{tabular}{|c|c|c|c|c|c|}
\hline Entry & Catalytic system $^{[a]}$ & Solvent & $\begin{array}{l}\Delta \\
{\left[{ }^{\circ} \mathrm{C}\right]}\end{array}$ & $\begin{array}{l}\text { Reaction } \\
\text { time }\end{array}$ & $\begin{array}{l}\text { Isolated yield } \\
\text { of } \mathbf{2}[\%]\end{array}$ \\
\hline 1 & Cat. $\mathrm{PdCl}_{2}\left(\mathrm{PPh}_{3}\right)_{2} / \mathrm{Cul}$ & $1: 8 \mathrm{Et}_{3} \mathrm{~N} / \mathrm{THF}$ & 20 & $7 d$ & 0 \\
\hline 2 & Cat. $\mathrm{PdCl}_{2} \mathrm{dppf} / \mathrm{Cul}$ & $1: 20 \mathrm{Et}_{3} \mathrm{~N} / \mathrm{Py}$ & 20 & $6 \mathrm{~d}$ & 0 \\
\hline 3 & Cat. $\mathrm{PdCl}_{2} \mathrm{dppf} / \mathrm{Cul}$ & 1:5 $\mathrm{Et}_{3} \mathrm{~N} /$ toluene & 55 & $6 d$ & 1.5 \\
\hline 4 & $\mathrm{Cul} / \mathrm{PPh}_{3} / \mathrm{K}_{2} \mathrm{CO}_{3}{ }^{[\mathrm{b}]}$ & DMF & 140 & $24 \mathrm{~h}$ & $<1$ \\
\hline
\end{tabular}

[a] 3-10 mol-\% in Pd cat.; [7] $=3 \times 10^{-2}-2 \times 10^{-1} \mathrm{~mol} \mathrm{~L}-1$. [b] 1:0.3:0.3:3 stoichiometric ratio of $7 / \mathrm{Cul}^{-} / \mathrm{PPh}_{3} / \mathrm{K}_{2} \mathrm{CO}_{3}$; $[7]=1 \times 10^{-1} \mathrm{~mol} \mathrm{~L}$. 
conditions. We therefore reasoned that a more detailed investigation into the Stephens-Castro-mediated cyclotrimerization of $\mathbf{8}$ would afford the best possibility for optimizing the yield of 2.

Ethynylcuprates are known to be aggregated in the solid state via a variety of T-shaped $\mathrm{Cu}^{\prime}$-ethyne, $\mathrm{Cu}^{\prime}-\mathrm{Cu}^{\prime}$ and ethynes bridging multiple $\mathrm{Cu}^{\prime}$ centres, forming a range of polymeric and cluster structures. ${ }^{[59]}$ We therefore initially reasoned that the presence of excess $\mathrm{Cu}^{\prime}$ may saturate and break up such polymers to generate soluble species that are more amenable cyclization. The fact that Eglinton et al. ${ }^{[2]}$ generated the ethynylcuprate under aqueous conditions was also of concern, in that possible presence of a trace of water in $\mathbf{8}$ may be detrimental to cyclization. We therefore investigated the effect of [CuX] on a modified Stephens-Castro cyclotrimerization in which $t \mathrm{BuOCu}$ was used as the in-situ metallation reagent under anhydrous conditions. ${ }^{[42]}$ The results of these investigations are shown in Table 2.

In entries 1-4 of Table 2, a 1:3:1 molar ratio of $7 / \mathrm{CuX} / \mathrm{tBuOK}$ was employed, which ensured the generation of a 1:2 molar ratio of ethynylcuprate $\mathbf{8 / C u X}$, i.e. $\mathbf{8}$ in the presence of excess CuX. In all four cases, the yield of 2 was improved (9-19\%) compared to that of our initial preparation of $\mathbf{2}$ ( $5 \%$ yield) using classical Stephens-Castro conditions, ${ }^{[58]}$ and showed no overall correlation with respect to changes in anion $\mathrm{X}(\mathrm{X}=\mathrm{Cl}, \mathrm{I})$ and the ageing time of $\mathbf{8}$ (entries 1, 2 and 4 . Table 2). The most dilute reaction (entry 3, Table 2) afforded the highest yield of $\mathbf{2}$ at this stage in the investigations of $19 \% .^{[60]}$ However, not a trace of $\mathbf{2}$ was isolated from the reaction in which the amount of CuX was further increased to a 1:5 molar ratio of $\mathbf{8 / C u X}$ (entry 5 , Table 2). Thus, although the $t \mathrm{BuOCu}$ cupration route is supe- rior to the classical Stephens-Castro conditions, the presence of a relatively large excess of $\mathrm{Cu}^{\prime}$ in the form of $\mathrm{CuX}$ halides has a detrimental effect upon the yield of $\mathbf{2}$.

We next investigated the effect of excess $t \mathrm{BuOCu}$ on the formation of $\mathbf{2}$, in which increasing quantities of $t \mathrm{BuOCu}$ were generated in situ in the presence of $\mathbf{8}$, with the following stoichiometric ratios: $\mathbf{8 / t B u O C u}$ of 1:1 (entries 6-13, Table 2), 1:2 (entries 14-16, Table 2) and 1:3 (entry 17, Table 2). With the exception of entry 12 , the yields of $\mathbf{2}$ in pyridine were significantly improved relative to the previous CuX additive experiments, varying between 21 and $36 \%$. No correlations were observed between yields of $\mathbf{2}$ and the nature of the anion ( $\mathrm{X}=$ $\mathrm{Cl}, \mathrm{I})$, the ageing time of $\mathbf{8}$ for $\mathbf{8} / \mathrm{tBuOCu}$ ratios of $1: 1$, and minor changes in heating time (16-18 h). The presence of $\mathrm{PPh}_{3}$ (entry 11, Table 2) exerted no significant effect upon the yield of 2 compared to the natural yield variation of the reaction performed repeatedly under similar conditions in the absence of phosphine (entry 6, Table 2). Ultrasonication (entry 9, Table 2) and dilution (entry 10, Table 2) shifted the yield of $\mathbf{2}$ to the lower end of the range ( 23 and $21 \%$ respectively), while DMF was revealed to be an inferior solvent for the reaction, reducing the yield of $\mathbf{2}$ to $17 \%$ (entry 13, Table 2). The presence of $\mathrm{P}(\text { nOct })_{3}$ however, completely blocked the formation of $\mathbf{2}$ (entry 12, Table 2); in parallel to experimental observations discussed later in the text.

Further increasing the amount of free $t \mathrm{BuOCu}$ in the reaction from molar ratios of $\mathbf{8} /$ tBuOCu of $1: 4$ (entry 18 , Table 2 ) to $1: 5$ (entry 20, Table 2) to $1: 9$ (entry 21, Table 2), with $3 \mathrm{~h}$ ageing times for $\mathbf{8}$, completely suppresses the formation of $\mathbf{2}$, mirroring the effect of excess CuX. However, increasing the ageing time of 8 from 3 to $20 \mathrm{~h}$, in the experiment employing a 1:4 molar

Table 2. Influence of excess $\mathrm{Cu}^{\prime}$ upon the Stephens-Castro mediated cyclization yields of 2, using tBuOCu as the metallating agent.

\begin{tabular}{|c|c|c|c|c|c|c|c|}
\hline Entry & $\begin{array}{l}\text { 7:CuX: } \\
\text { tBuOK molar ratio }{ }^{[a]}\end{array}$ & $\mathrm{x}$ & Solvent & $\begin{array}{l}\text { Ageing time of } \\
\mathbf{8}[\mathrm{h}]\end{array}$ & $\begin{array}{l}\Delta \\
{\left[{ }^{\circ} \mathrm{C}\right]}\end{array}$ & $\begin{array}{l}\text { Heating time } \\
\text { [h] }\end{array}$ & $\begin{array}{l}\text { Isolated yield } \\
\text { of } \mathbf{2}[\%]\end{array}$ \\
\hline 1 & 1:3:1 & $\mathrm{Cl}$ & Py & 19 & 140 & 18 & 13 \\
\hline 2 & 1:3:1 & $\mathrm{Cl}$ & Py & 7 & 140 & 18 & 14 \\
\hline 3 & 1:3:1 & $\mathrm{Cl}$ & Py (dilute) ${ }^{[b]}$ & 1 & 140 & 18 & 19 \\
\hline 4 & 1:3:1 & 1 & Py & 0.25 & 140 & 18 & $9-10$ \\
\hline 5 & $1: 6: 1$ & $\mathrm{Cl}$ & Py & 0.42 & 140 & 18 & 0 \\
\hline 6 & $1: 2: 2$ & $\mathrm{Cl}$ & Py & $3-18$ & 140 & 16 & $24-36$ \\
\hline 7 & $1: 2: 2$ & 1 & Py & 5 & 140 & 18 & 26 \\
\hline 8 & $1: 2: 2$ & $\mathrm{Cl}$ & Py & 3 & 120 & 18 & 30 \\
\hline 9 & $1: 2: 2$ & $\mathrm{Cl}$ & Py & $4 \mathrm{~h}$ ultrasonicn. ${ }^{[\mathrm{c}]}$ & 140 & 17 & 23 \\
\hline 10 & $1: 2: 2$ & $\mathrm{Cl}$ & Py (dilute) ${ }^{[\mathrm{d}]}$ & 2 & 140 & 18 & 21 \\
\hline 11 & $1: 2: 2+$ 2eq $\mathrm{PPh}_{3}$ & $\mathrm{Cl}$ & Py & 3 & 140 & 18 & 28 \\
\hline 12 & $1: 2: 2+2$ eq $\mathrm{P}(n \mathrm{Oct})_{3}$ & $\mathrm{Cl}$ & Py & 4 & 140 & 18 & 0 \\
\hline 13 & $1: 2: 2$ & $\mathrm{Cl}$ & DMF & 5 & 140 & 18 & 17 \\
\hline 14 & $1: 3: 3$ & $\mathrm{Cl}$ & Py & 2 & 140 & 19 & 24 \\
\hline 15 & 1:3:3 & $\mathrm{Cl}$ & Py & 3 & 140 & 16 & 29 \\
\hline 16 & $1: 3: 3$ & $\mathrm{Cl}$ & Py & 16 & 140 & 19 & 33 \\
\hline 17 & $1: 4: 4$ & $\mathrm{Cl}$ & Py & 4 & 140 & 18 & 26 \\
\hline 18 & $1: 5: 5$ & $\mathrm{Cl}$ & Py & 3 & 140 & 18 & 0 \\
\hline 19 & $1: 5: 5$ & $\mathrm{Cl}$ & Py & 20 & 140 & 20 & 24 \\
\hline 20 & $1: 6: 6$ & $\mathrm{Cl}$ & Py & 3 & 140 & 17 & 0 \\
\hline 21 & 1:10:10 & $\mathrm{Cl}$ & Py & 3 & 140 & 18 & 0 \\
\hline
\end{tabular}

[a] General experimental procedures are detailed in the Supporting Information. [b] Cyclization conducted in $45 \mathrm{~mL}$ of solvent. [c] After $0.3 \mathrm{~h}$ ultrasonication, a further $5 \mathrm{~mL}$ of pyridine added to give total reaction volume of $13 \mathrm{~mL}$, in order to fluidify and homogenize suspension. Ultrasonication performed at a water bath temp. of $25-30{ }^{\circ} \mathrm{C}$. [d] 7 was added as a solution in $10 \mathrm{~mL}$ of pyridine to the $t$ BuOCu in $160 \mathrm{~mL}$ of pyridine, to give a total reaction volume of $170 \mathrm{~mL}$. 
ratio of $\mathbf{8} /$ tBuOCu (entry 19 , Table 2 ), resulted in an improved yield of 2, which was isolated in $24 \%$. This behavior parallels the trend observed in the $1: 2 \mathrm{~mol}$ ratio experiments of $\mathbf{8} / \mathrm{tBuOCu}$ (entries 14-16, Table 2), in which increasing the ageing time of $\mathbf{8}$ from $2-16 \mathrm{~h}$ causes an increase in yield of $\mathbf{2}$ from 24-33\%.

Thus the negative effect of excess $\mathrm{Cu}^{\prime}$ (in the form of $\mathrm{CuX}$ and $t \mathrm{BuOCu}$ ) on the yield of $\mathbf{2}$ is consistent with breakup or reorganization of the organometallic species responsible for subsequent cyclization. The fact that the yield of $\mathbf{2}$ increases with the ageing time of $\mathbf{8}$ in the presence of relatively high concentrations of $t \mathrm{BuOCu}$, suggests however that a structural reorganization of associations of $\mathbf{8}$ in the presence of excess $t \mathrm{BuOCu}$ is occurring, that enables the species necessary for the successful cyclization to be slowly regenerated over time. ${ }^{[61]}$

\section{Influence of Reaction Conditions on the Stoichiometric Stephens-Castro Mediated Cyclotrimerization Yield of 2 and 3}

We then investigated the effect of experimental conditions on the yield of $\mathbf{2}$ employing stoichiometric molar ratios of 2-iodoarylethyne/Cul/base. In an attempt to prepare $\mathbf{3}$, the conditions optimal for the generation of $\mathbf{2}$ were also applied to the cyclization of ethynylcuprate $\mathbf{1 0}$. The results of these investigations are detailed in Table 3.

In entries 1 and 2, we investigated the influence of added phosphines on the yields of $\mathbf{2}$, employing a 1:1 molar ratio of $\mathbf{8} / \mathrm{PR}_{3}$. In entries $3-8$ of Table 3 , the reactions were performed under related conditions in the absence of $\mathrm{PPh}_{3}$, and afforded similar yields of $2(26-36 \%)$, showing that the presence of $\mathrm{PPh}_{3}$ had no significant effect upon the yield of $\mathbf{2}$. In contrast, addition of $\mathrm{P}(n \mathrm{Oct})_{3}$ completely suppressed the cyclotrimerization. This behavior was identical to that observed for parallel experiments with excess tBuOCu (entries 11 and 12, Table 2) described above. For entries 3-8 of Table 3, no correlation was observed between the yield of $\mathbf{2}$ and the ageing and heating times of $\mathbf{8}$, except in entry 3 of Table 3 . In this latter case, the comparatively short heating time at the lower temperature limit for cyclization resulted in a slightly lower yield of $\mathbf{2}$ due to incomplete consumption of $\mathbf{8}$. The effect of inverse addition i.e. the addition of the $t \mathrm{BuOCu}$ solution to $\mathbf{7}$ (entry 8, Table 3 ) also had no significant effect upon the yield of 2. In entries 9-11 of Table 3 we explored the effect of reaction medium upon the yield of 2. 4-tBu-pyridine and benzonitrile were found to be marginally deleterious to the yield of $\mathbf{2}$. However, in 1-methyl-

Table 3. Influence of reaction conditions upon the yields of $\mathbf{1 - 3}$, using a 1:1:1:1 equivalence ratio of 2-iodoarylethyne/Cul/base/PR 3 when present.

\begin{tabular}{|c|c|c|c|c|c|c|c|}
\hline Entry & $\begin{array}{l}\text { 2-iodoaryl } \\
\text { ethyne }\end{array}$ & $\begin{array}{l}\text { Cul/base/ } \\
\left(\mathrm{PR}_{3}\right)^{[\mathrm{a}]}\end{array}$ & Solvent & $\begin{array}{l}\text { Ethynylcuprate } \\
\text { ageing time [h] }\end{array}$ & $\begin{array}{l}\Delta \\
{\left[{ }^{\circ} \mathrm{C}\right]}\end{array}$ & $\begin{array}{l}\text { Heating time } \\
\text { [h] }\end{array}$ & $\begin{array}{l}\text { Isolated yield } \\
\text { [\%] }\end{array}$ \\
\hline 1 & 7 & $\mathrm{Cul} / \mathrm{tBuOK} / \mathrm{PPh}_{3}$ & Py & 6 & 120 & 13 & $33(2)$ \\
\hline 2 & 7 & $\mathrm{Cul} / \mathrm{tBuOK} / \mathrm{P}(n \mathrm{Oct})_{3}$ & Py & 6 & 120 & 13 & $0(2)$ \\
\hline 3 & 7 & $\mathrm{Cul} / \mathrm{tBuOK}$ & Py & 18 & 120 & 2 & $26^{[\mathrm{b}]}(\mathbf{2})$ \\
\hline 4 & 7 & $\mathrm{Cul} / \mathrm{tBuOK}$ & Py & 18 & 120 & 18 & $34(2)$ \\
\hline 5 & 7 & $\mathrm{Cul} / \mathrm{tBuOK}$ & Py & 18 & 130 & 1 & $34(2)$ \\
\hline 6 & 7 & $\mathrm{Cul} / \mathrm{tBuOK}$ & Py & 4 & 130 & 18 & $36(2)$ \\
\hline 7 & 7 & $\mathrm{Cul} / \mathrm{tBuOK}$ & Py & 68 & 130 & 20 & $34(2)$ \\
\hline 8 & 7 & $\mathrm{Cul} / \mathrm{tBuOK}$ & Py & 4 & 130 & 17 & $34^{[c]}(2)$ \\
\hline 9 & 7 & $\mathrm{Cul} / \mathrm{tBuOK}$ & 4-tBu-Py & 6 & 130 & 18 & $27(2)$ \\
\hline 10 & 7 & $\mathrm{Cul} / \mathrm{tBuOK}$ & $\mathrm{PhCN}$ & 4 & 130 & 18 & $27(2)$ \\
\hline 11 & 7 & $\mathrm{Cul} / \mathrm{tBuOK}$ & 1-methyl-morpholine & 19 & 130 & 18 & $8^{[\mathrm{b}]}(2)$ \\
\hline 12 & 7 & $\mathrm{Cul} / \mathrm{LiN}(\mathrm{iPr})_{2}^{[\mathrm{d}]}$ & Py & 4 & 130 & 14 & $36(2)$ \\
\hline 13 & 7 & $\mathrm{Cul} / \mathrm{K}_{2} \mathrm{CO}_{3}{ }^{\text {[e] }}$ & Py & 4 & 130 & 14 & $35(2)$ \\
\hline 14 & 7 & $\mathrm{Cul} / \mathrm{K}_{2} \mathrm{CO}_{3}^{[\mathrm{e}]}$ & DMF & 4 & 130 & 14 & $19(2)$ \\
\hline 15 & 7 & $\mathrm{Cul} / \mathrm{tBuOK}$ & Py & 18 & 140 & 1 & $31(2)$ \\
\hline 16 & 7 & $\mathrm{Cul} / \mathrm{tBuOK}$ & Py & 18 & 150 & 1 & $36(2)$ \\
\hline 17 & 7 & Cul/tBuOK & Py & 18 & 150 & 12 (in $p$-xylene) ${ }^{[\mathrm{f}]}$ & $8^{[\mathrm{b}]}(2)$ \\
\hline 18 & 7 & Cul/tBuOK & Py & 18 & 170 & 1 & $33(2)$ \\
\hline 19 & 9 & $\mathrm{Cul} / \mathrm{tBuOK}$ & Py & 4 & 140 & 12 & $0(3)$ \\
\hline 20 & 9 & $\mathrm{Cul} / \mathrm{K}_{2} \mathrm{CO}_{3}^{[\mathrm{e}]}$ & Py & 4 & 140 & 12 & $0(3)$ \\
\hline 21 & 5 & $\mathrm{Cul} / \mathrm{tBuOK}$ & DMF & 4 & 140 & 18 & $50(1)$ \\
\hline 22 & 5 & $\mathrm{Cul} / \mathrm{tBuOK}$ & Py & 4 & 140 & 18 & $61(1)$ \\
\hline 23 & 5 & $\mathrm{Cul} / \mathrm{tBuOK}$ & Py (dilute) ${ }^{[g]}$ & 4 & 140 & 18 & $38(1)$ \\
\hline 24 & 5 & $\mathrm{Cul} / \mathrm{tBuOK} / \mathrm{PPh}_{3}$ & Py & 4 & 140 & 18 & $58(1)$ \\
\hline 25 & 5 & $\mathrm{Cul} / \mathrm{tBuOK}$ & $\mathrm{Py} / 10 \% \mathrm{H}_{2} \mathrm{O}$ & $7^{[\mathrm{h}]}$ & 140 & 18 & $51(1)$ \\
\hline 26 & 5 & $\mathrm{Cul} / \mathrm{K}_{2} \mathrm{CO}_{3}{ }^{[\mathrm{e}]}$ & Py & 4 & 140 & 18 & $53(1)$ \\
\hline 27 & 5 & $\mathrm{Cul} / \mathrm{K}_{2} \mathrm{CO}_{3}^{[\mathrm{e}]}$ & DMF & 4 & 140 & 18 & $62(1)$ \\
\hline 28 & 5 & $\mathrm{Cul} / \mathrm{K}_{2} \mathrm{CO}_{3}{ }^{[\mathrm{e}]} / \mathrm{PPh}_{3}$ & DMF & 4 & 140 & 18 & $53(1)$ \\
\hline 29 & 5 & $\mathrm{Cul} / \mathrm{K}_{2} \mathrm{CO}_{3}^{[\mathrm{e}]}$ & $\mathrm{DMF} / 10 \% \mathrm{H}_{2} \mathrm{O}$ & $7^{[\mathrm{h}]}$ & 140 & 18 & $48(1)$ \\
\hline 30 & 5 & $\mathrm{Ag}_{2} \mathrm{CO}_{3}$ & DMF & 20 & $170^{[i]}$ & 18 & $0(\mathbf{1})^{[j]}$ \\
\hline
\end{tabular}

[a] See General Experimental Methods. [b] Reaction incomplete. Yield based upon 2-iodoarylethyne consumed. [c] Inverse addition; tBuOCu reaction was syringed onto a stirred solution of 2-iodoarylethyne in $1 \mathrm{~mL}$ of pyridine to give a total volume of $10 \mathrm{~mL}$. [d] The LiN(iPr) ${ }_{2}$ was syringed into a stirred solution of Cul in pyridine. [e] A 1:1:0.6 molar ratio of 2-iodoarylethyne/Cul/ $\mathrm{K}_{2} \mathrm{CO}_{3}$ was employed. [f] After stirring for $18 \mathrm{~h}$, the pyridine was removed from the ethynylcuprate by distillation under vacuum, and replaced with an equivalent volume of $p$-xylene under argon. [g] $200 \mathrm{~mL}$ total reaction volume. [h] After stirring for $4 \mathrm{~h}$, deoxygenated water was added and stirring continued for a further $3 \mathrm{~h}$ before heating. [i] No observable reaction at $140{ }^{\circ} \mathrm{C}$. [j] $\approx 10 \%$ yield 1,4-bis(2-iodophenyl)buta-1,3-diyne was isolated. 
morpholine, the yield of 2 was reduced to $8 \%$, and the progress of the reaction significantly retarded. ${ }^{[62]}$ The use of the alternative bases $\mathrm{LiN}(\mathrm{iPr})_{2}$ and $\mathrm{K}_{2} \mathrm{CO}_{3}$ in pyridine exerted little effect upon the yield of $\mathbf{2}$ (entries 12 and 13, Table 3) compared to the use of tBuOK (cf. for example entry 6, Table 3). However, DMF caused a significant lowering in the yield of 2 when $\mathrm{K}_{2} \mathrm{CO}_{3}$ was used as base (entry 14, Table 3 ).

In entries 15, 16 and 18 of Table 3, the effect of higher reaction temperatures showed no significant deleterious effect upon the yield of $\mathbf{2}$, highlighting its thermal stability. In the case of entry 17 , the ethynylcuprate $\mathbf{8}$ was prepared in an identical way as in entries 15,16 and 18 of Table 3, but then the pyridine removed and the heating stage conducted in $o$-xylene. As with 1-methylmorpholine, 0 -xylene appears to be a nonsolvent for $\mathbf{8}$, whereas in pyridine, 4-tBu-pyridine and DMF, it is sparingly soluble, imparting a slight coloration to the surrounding medium.

The experiments in entries 11 and 17 of Table 3 confirm that solubilization of $\mathbf{8}$ is essential for successful thermal generation of $\mathbf{2}$. In the case of the $\mathrm{Cul} / \mathrm{tBuOK}$ systems, it therefore appears to be the action of pyridine on the sparingly soluble $\mathbf{8}$ that is the main factor generating and solubilizing the structural form of $\mathbf{8}$ responsible for assisting the cyclotrimerization step. Further support for the conclusion that a soluble form of $\mathbf{8}$ is the most likely candidate directing the cyclization process was observed for entry 13 of Table 3, which employed $\mathrm{Cul} / \mathrm{K}_{2} \mathrm{CO}_{3}$ in pyridine as the metallating reagent. This latter reaction appeared as a pale yellow solution throughout the entire ethynylcuprate ageing and initial heating steps, yet the yield of $\mathbf{2}$ was similar to that obtained using $\mathrm{Cul} / \mathrm{tBuOK}$ in pyridine, in which the bulk of $\mathbf{8}$ was always present as a precipitated solid (entries 4-8, Table 3). ${ }^{[63]}$

With a method in hand for preparing 2 in acceptable and reproducible yields, we employed similar reaction conditions for the attempted synthesis of the isomeric 3 from 9 (Scheme 3). In this case, the addition of $\mathbf{9}$ to mixtures of $\mathrm{Cul} / \mathrm{tBuOK}$ and $\mathrm{Cul} /$ $\mathrm{K}_{2} \mathrm{CO}_{3}$ under comparable conditions generated ethynylcuprate 10 in situ, which was observed as a khaki precipitate in the former reaction (entries 19 and 20, Table 3). However subsequent heating and workup of each reaction yielded not a trace of 3, or any other clearly characterizable by-products.

Thus, the presence of metal coordinating pyridine nitrogens ortho- to the site of cyclization appears to suppress the cyclotrimerization of $\mathbf{1 0}$ to $\mathbf{3}$.

\section{Influence of Reaction Conditions on the Stoichiometric Stephens-Castro Mediated Cyclotrimerization Yield of 1}

In order to assess the broader generality of the reaction conditions found optimal for the generation of $\mathbf{2}$, we also reinvestigated the Stephens-Castro mediated cyclization of ethynylcuprate 6 to 1, the results of which are shown in the lower part of Table 3.

As in the synthesis of $\mathbf{2}$, the solvent was found to influence the cyclization yield of $\mathbf{1}$. In the $t$ BuOCu metallating system, the use of pyridine rather than DMF was found to afford superior yields of 1 (cf. entries 21 and 22, Table 3). For the $\mathrm{Cul} / \mathrm{K}_{2} \mathrm{CO}_{3}$ metallating system, the reaction conducted in DMF gave a higher yield of $\mathbf{1}$ compared to that in pyridine (entries 26 and 27, Table 3). This latter finding however was the reverse of the solvent effect seen for the generation of $\mathbf{2}$, where pyridine was found to be a superior to DMF for the $\mathrm{Cul} / \mathrm{K}_{2} \mathrm{CO}_{3}$ metallating system (entries 13 and 14, Table 3). Solvent effects in the Stephens/Castro mediated cyclotrimerization appear therefore to be substrate specific.

When in its preferred solvent medium, the nature of the metallating system has little effect upon the yield of 1, which reaches a common optimum of 61-62\% (entries 22 and 27, Table 3). Performing the reaction under medium dilution conditions causes a reduction in the yield of $\mathbf{1}$ (cf. entries 22 and 23, Table 3), ${ }^{[64]}$ as does the presence of water in the thermal cyclization step (cf. entries 22/25 and 27/29, Table 3). Addition of $\mathrm{PPh}_{3}$ to the $t \mathrm{BuOCu}$ metallating system exerted little effect upon the yield of 1 (cf. entries 22 and 24, Table 3), mirroring that seen for 2 (cf. entries 6 and 11, Table 2). However, the presence of $\mathrm{PPh}_{3}$ in the $\mathrm{Cul} / \mathrm{K}_{2} \mathrm{CO}_{3} / \mathrm{DMF}$ system may be detrimental to the yield of 1, when added in stoichiometric quantities (cf. entries 27 and 28, Table 3).

By contrast, the use of $\mathrm{Ag}_{2} \mathrm{CO}_{3}$ in place of $\mathrm{Cul} / \mathrm{K}_{2} \mathrm{CO}_{3}$ in DMF completely suppressed the cyclotrimerization (entry 30, Table 3), again emphasizing the crucial role that the structure of the $\mathrm{Cu}^{\prime}$ oligomeric and/or polymeric aggregates must play in directing the course of the cyclization.

\section{A Reinvestigation into the Formation of 1 via the Catalytic Modification of the Stephens-Castro Mediated Cyclotrimerization}

The finding that stoichiometric excesses of copper reagents were unfavorable to the cyclization of $\mathbf{7}$ to $\mathbf{2}$, suggested that catalytic quantities of Cu' may be more advantageous. However, investigations into this possibility were thwarted by the thermal instability of ortho-iodoethynylpyridine 7, which decomposed at a faster rate than its conversion to the more stable ethynylcuprate 8 by the recycled $\mathrm{Cu}^{\prime}$ catalyst (entry 4, Table 1). We therefore decided to reinvestigate the $\mathrm{Cul} / \mathrm{PPh}_{3} / \mathrm{K}_{2} \mathrm{CO}_{3}$ catalyzed Stephens-Castro mediated cyclization of $\mathbf{6}$ to $\mathbf{1}^{[25]}$ verses the use of $\mathrm{Cul} / \mathrm{PPh}_{3} / \mathrm{tBuOK}$, both with and without phosphine, in order to obtain more insight into the influence of the nature of the catalyst on the cyclization yield. The results of these studies are shown in Table 4.

As a control, we repeated the exact procedure of lyoda et al., and obtained a $59 \%$ yield of 1 (entry 1, Table 4), which compared favorably with the reported yield of 1 of $55 \%$. $^{[25]}$ We then repeated the reaction in the absence of added $\mathrm{PPh}_{3}$ and under milder conditions, i.e. longer ageing time for the formation of $\mathbf{6}$ and lower heating temperature (entry 2, Table 4). These modifications to the reported conditions resulted in an increase in the yield of 1 to $64 \%$. Reducing the amount of Cul from a molar ratio of $\mathbf{5 / C u l ~ o f ~ 1 : 0 . 3 ~ t o ~ 1 : 0 . 1 ~ i n ~ t h e ~ p h o s p h i n e - ~}$ free reaction caused a significant drop in the yield of 1 to $27 \%$, and required a much longer heating time to effect complete consumption of 5 (entry 3, Table 4). When the former reaction was conducted using $\mathrm{KHCO}_{3}$ in place of $\mathrm{K}_{2} \mathrm{CO}_{3}$, a comparable 
Table 4. An exploration of the effect of phosphines and solvent on the yields of $\mathbf{1}$ using catalytic quantities of Cul.

\begin{tabular}{|c|c|c|c|c|c|c|}
\hline Entry & $\begin{array}{l}\text { Reaction components }{ }^{[a]} \\
\text { (molar ratio) }\end{array}$ & Solvent & $\begin{array}{l}\text { Cuprate ageing } \\
\text { time }[\mathrm{h}]\end{array}$ & $\begin{array}{l}\Delta \\
{\left[{ }^{\circ} \mathrm{C}\right]}\end{array}$ & $\begin{array}{l}\text { Heating } \\
\text { time }[\mathrm{h}]^{[\mathrm{b}]}\end{array}$ & $\begin{array}{l}\% \text { isolated } \\
\text { yield of } 1\end{array}$ \\
\hline 1 & $\begin{array}{l}\text { 5/Cul/ } / \mathrm{PPh}_{3} / \mathrm{K}_{2} \mathrm{CO}_{3} \\
(1: 0.3: 0.3: 3)\end{array}$ & DMF & 0 & 160 & 24 & 59 \\
\hline 2 & $\begin{array}{l}\mathbf{5} / \mathrm{Cul} / \mathrm{K}_{2} \mathrm{CO}_{3}{ }^{[\mathrm{c}]} \\
(1: 0.3: 0.6)\end{array}$ & DMF & 4 & 140 & 26 & 64 \\
\hline 3 & $\begin{array}{l}5 / \mathrm{Cul} / \mathrm{K}_{2} \mathrm{CO}_{3}{ }^{[\mathrm{c}]} \\
(1: 0.1: 0.6)\end{array}$ & DMF & 4 & 140 & $72^{[\mathrm{d}]}$ & 27 \\
\hline 4 & $\begin{array}{l}\mathbf{5} / \mathrm{Cul} / \mathrm{KHCO}_{3} \\
(1: 0.3: 1.2)\end{array}$ & DMF & 4 & 140 & 18 & 60 \\
\hline 5 & $\begin{array}{l}\text { 5/Cul/ } / \mathrm{MeCO}_{2} \mathrm{~K}^{[\mathrm{e}]} \\
(1: 0.3: 1.2)\end{array}$ & DMF & 4 & 140 & 26 & 35 \\
\hline 6 & $\begin{array}{l}5 / \mathrm{Cul} / \mathrm{P}(n \mathrm{nBu})_{3} / \mathrm{K}_{2} \mathrm{CO}_{3}{ }^{[\mathrm{Cc}]} \\
(1: 0.3: 0.3: 0.6)\end{array}$ & DMF & 4 & 140 & 18 & 35 \\
\hline 7 & $\begin{array}{l}\text { 5/Cul/P(nOct })_{3} / \mathrm{K}_{2} \mathrm{CO}_{3}{ }^{[\mathrm{c}]} \\
(1: 0.3: 0.3: 0.6)\end{array}$ & DMF & 4 & 140 & 18 & 21 \\
\hline 8 & $\begin{array}{l}\mathbf{5} / \mathrm{Cul} / \mathrm{PPh}_{3} / \mathrm{K}_{2} \mathrm{CO}_{3} \\
(1: 0.3: 0.3: 3)\end{array}$ & Py & 0 & 160 & 24 & 44 \\
\hline 9 & $\begin{array}{l}5 / \mathrm{Cul} / \mathrm{K}_{2} \mathrm{CO}_{3}{ }^{[c]} \\
(1: 0.3: 0.6)\end{array}$ & Py & 4 & 140 & 72 & 41 \\
\hline 10 & $\begin{array}{l}\mathbf{5} / \mathrm{Cul} / \mathrm{PPh}_{3} / \mathrm{tBuOK} \\
(1: 0.3: 0.3: 1.2)\end{array}$ & DMF & 4 & 140 & 96 & 23 \\
\hline 11 & $\begin{array}{l}\mathbf{5} / \mathrm{Cul} / \mathrm{tBuOK} \\
(1: 0.3: 1.2)\end{array}$ & DMF & 4 & 140 & 96 & 28 \\
\hline 12 & $\begin{array}{l}\text { 5/Cul/PPh } / \text { /BuOK } \\
(1: 0.3: 0.3: 1.2)\end{array}$ & Py & 2 & 140 & 18 & 24 \\
\hline 13 & $\begin{array}{l}\mathbf{5} / \mathrm{Cul} / \mathrm{tBuOK} \\
(1: 0.3: 1.2)\end{array}$ & Py & 2 & 140 & 18 & 23 \\
\hline
\end{tabular}

[a] The cupration reagents were generated as described in the General Experimental Methods, as were the phosphine and 2-iodoarylethyne addition procedures, to give total reaction volumes of $10 \mathrm{~mL}$. [b] Time at which 2-iodoarylethyne is completely consumed, as determined by TLC sampling. [c] A 1:0.6 molar ratio of 2-iodoarylethyne $/ \mathrm{K}_{2} \mathrm{CO}_{3}$ was employed. [d] Reaction rate much slower at a 10 mol-\% catalyst loading. [e] Dried under vacuum at $100{ }^{\circ} \mathrm{C}$ directly before use.

yield of $60 \%$ of 1 was obtained (entry 4 , Table 4 ), whereas the use of $\mathrm{MeCO}_{2} \mathrm{~K}$ as base resulted in a yield reduction of $\mathbf{1}$ to $35 \%$ (entry 5, Table 4). The use of the more strongly coordinating, comparatively electron rich phosphines, $\mathrm{P}(t \mathrm{Bu})_{3}$ and $\mathrm{P}(n \mathrm{Oct})_{3}$ reduced the cyclization yields of 1 to 35 and $21 \%$ respectively (entries 6 and 7, Table 4), an effect that has been observed in the acyclic catalytic Stephens-Castro coupling. ${ }^{[65]}$ A reduction in the yield of $\mathbf{1}$ also occurred when the cyclization conditions of lyoda et al., ${ }^{[25]}$ were repeated in pyridine, and in the same solvent under milder conditions in the absence of $\mathrm{PPh}_{3}$ (entries 8 and 9, Table 4). In the latter entry, performed under milder conditions, the reaction appeared to proceed much more slowly than in DMF (cf. entry 2, Table 4), requiring a $72 \mathrm{~h}$ heating time in order for all the $\mathbf{5}$ to be consumed.

In contrast, the $t \mathrm{BuOCu}$ mediated cyclization with catalytic $\mathrm{Cu}^{\prime}$ conducted both in DMF and pyridine in the presence and absence of $\mathrm{PPh}_{3}$ afforded 1 in comparatively moderate yields of $23-28 \%$ (entries $10-13$, Table 4). Thus, if a catalytic process is operative, it is significantly less efficient compared to the reactions with carbonate as base. ${ }^{[6]}$ The reaction was also observed to proceed much more slowly in DMF than in pyridine, a reversal of the solvent rate effect seen for the analogous $\mathrm{Cul} / \mathrm{K}_{2} \mathrm{CO}_{3}$ catalyzed cyclizations (cf. entries 2 and 9, Table 4).

As in the stoichiometric reactions described in Table 3, the effect of the phosphine on the catalytic cyclization yield is negligible $^{[67]}$ or even detrimental, depending upon its electronic properties. The results in Table 4 show that it is the $\mathrm{CO}_{3}{ }^{2-}$ / $\mathrm{HCO}_{3}{ }^{-}$anions that play a major role in stabilizing and recycling the $\mathrm{Cu}^{\prime}$ in the catalytic cyclization process, with DMF as the favored solvent, to give a process that is self-catalytic with respect to Cul alone (i.e. independent of phosphine).

\section{An Investigation into the Nature of Oligomer Growth Leading to Cyclization}

In a classical cyclization process, the formation of $\mathbf{2}$ and $\mathbf{4}$ would be expected to proceed via a stepwise process in which monomer $\mathbf{8}$ first combines with another monomer $\mathbf{8}$ to afford $\mathbf{1 6}$ (Scheme 4).

Intermediate $\mathbf{1 6}$ may then react further with a molecule of 8 to yield a trimer oligomer that can intramolecularly cyclize to 2. Dimer $\mathbf{1 6}$ may also be expected to intermolecularly couple with another molecule of $\mathbf{1 6}$ to give a tetramer oligomer that can cyclize to give $\mathbf{4}$; the latter of which may also be expected to result from the stepwise reaction of $\mathbf{1 6}$ with a further two molecules of $\mathbf{8}$ (Scheme 4). Alternatively, in a situation in which three or four molecules of $\mathbf{8}$ are juxtapositioned within some type of supramolecular aggregate or template, then a concerted process may be possible in which the appropriate number of monomer units of $\mathbf{8}$ may simultaneously cyclize to give 2 and 4, and with little or no intermediacy of $\mathbf{1 6}$ and higher oligomer intermediates.

In order to try to throw more light on the reaction pathway leading to cyclization, we independently synthesized 16 from 11 and 12 via 13, 14 and 15 as shown in Scheme 4, and 


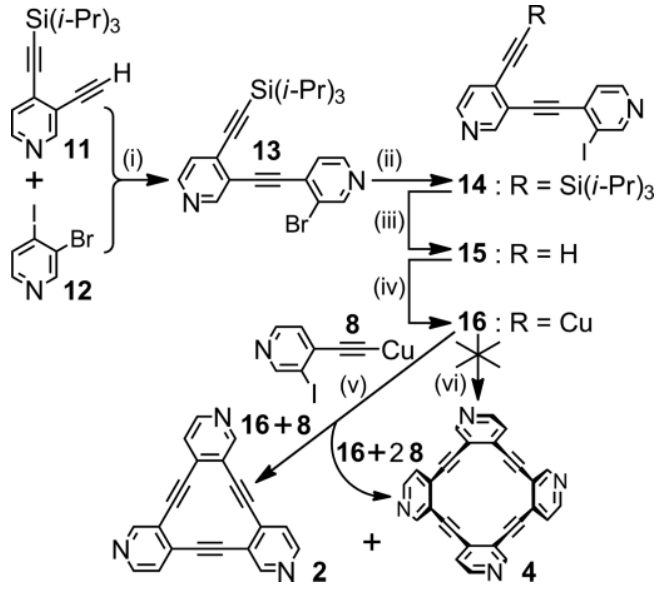

Scheme 4. Synthesis of $\mathbf{1 6}$, and its $1: 1$ stoichiometric reaction with $\mathbf{8}$ to give a mixture of $\mathbf{2}$ and $\mathbf{4}$, which may form via couplings with respectively one and two equivalents of 8 . (i) $\mathrm{PdCl}_{2}\left(\mathrm{PPh}_{3}\right)_{2} / \mathrm{Cul}$ cat./toluene/Et ${ }_{3} \mathrm{~N}$; (ii) a) $n \mathrm{BuLi} /$ $\mathrm{Et}_{2} \mathrm{O} /-78{ }^{\circ} \mathrm{C}$; b) $\mathrm{I}_{2}$; (iii) 1 equiv. of. $n \mathrm{Bu}_{4} \mathrm{NF} / \mathrm{THF}$; (iv) a) Cul/tBuOK/py, $1 \mathrm{~h}$; b) 15/18 h; (v) a) Cul/tBuOK/py, 1 h; b) addn. $7+15$ to generate $8+16$ in situ; c) $\Delta\left(135^{\circ} \mathrm{C}\right)$; (vi) $\Delta\left(135-150^{\circ} \mathrm{C}\right)$.

performed a 1:1 stoichiometric reaction of $\mathbf{1 6 / 8}$ under identical reaction conditions and concentration as Entry 4, Table 3, but with an elevated cyclization temperature of $135^{\circ} \mathrm{C}$. These conditions were chosen as they fell within the range of those that previously afforded the highest yields of 2 (Entries 4-8, 1516 , Table 3), while providing an organocuprate ageing time of sufficient length to ensure that all internal changes were essentially complete before heating to effect cyclization.

However, instead of the higher yield of $\mathbf{2}$, which would be expected of a stepwise reaction involving $\mathbf{1 6}$ as an intermediate, we obtained a much lower than expected yield of $\mathbf{2}$ and, although all starting materials were consumed, a much lower overall conversion to cyclic products ( $12 \%$ and $6 \%$ yields of $\mathbf{2}$ and $\mathbf{4}$ respectively; see Supporting Information). The crude reaction product also contained an unusually elevated ratio of $\mathbf{4} / \mathbf{2}$, the former of which was normally observed in only trace amounts starting from monomer $\mathbf{8}$ alone.

Surprisingly, when 16 alone was heated at $135{ }^{\circ} \mathrm{C}$ under identical conditions to the 1:1 reaction between $\mathbf{1 6}$ and 8 described above, it was found to be almost completely unreactive. A ${ }^{1} \mathrm{H}$ NMR of the crude reaction product isolated after further heating at $150{ }^{\circ} \mathrm{C}$ for $12 \mathrm{~h}$, showed it to comprise almost entirely of unreacted 15, along with only a trace of 4 , although $35 \%$ of the $\mathbf{1 5}$ had been consumed. As the expected product 4 was found to be thermally unstable above $140{ }^{\circ} \mathrm{C}$, it is possible that any $\mathbf{4}$ generated during the course of the reaction was decomposing as it was formed at $150{ }^{\circ} \mathrm{C}$. This suggests that the self-coupling of $\mathbf{1 6}$ does not constitute the principle source of the $\mathbf{4}$ generated during the 1:1 reaction between $\mathbf{1 6}$ and $\mathbf{8}$ as it would be unreactive at the reaction temperature of $135^{\circ} \mathrm{C}$.

The fact that the less reactive $\mathbf{1 6}$ was completely consumed during the $1: 1$ reaction between $\mathbf{1 6}$ and 8 at $135^{\circ} \mathrm{C}$, suggest that the product cycles $\mathbf{2}$ and $\mathbf{4}$ arise from reactions between 16 and the more reactive 8 (Scheme 4). Thus, the low yield of conversion to cyclic products and the suppression of the generation of $\mathbf{2}$ and enhancement of the yield of $\mathbf{4}$ in the
1:1 reaction between $\mathbf{1 6}$ and $\mathbf{8}$ therefore represents a significant contrast to that of the cyclotrimerization of $\mathbf{8}$ alone, which afforded higher yields of $\mathbf{2}$ with only traces of $\mathbf{4}$ (Entries 4-8, 15-16, Table 3). These findings suggest that 16 plays at most a minor role in the cyclotrimerization of $\mathbf{8}$ to $\mathbf{2}$, although it may be involved in the generation of tetramer $\mathbf{4}$. Although the exact cyclization mechanism is unknown, the factors enabling the cyclotrimerization of $\mathbf{8}$ to $\mathbf{2}$ may therefore more probably associated with the structure of intermolecular associations of $\mathbf{8}$ and how they are affected by the presence of structurally different ethynylcuprates such as $\mathbf{1 6}$.

\section{Thermochemical Investigations on DehydrotriaryI[12]- annulenes 1 and 2, and Ethynylcuprates 6, 8, 10 and 16}

In order to determine if differences in thermochemical stabilities of the ethynylcuprate precursors and/or the macrocyclic products were influencing the cyclization yields, we investigated the thermochemical stability of 1, 2, 6, 8, 10 and 16. Their thermogravimetric analysis (TGA) decomposition profiles are shown in Figure 1.
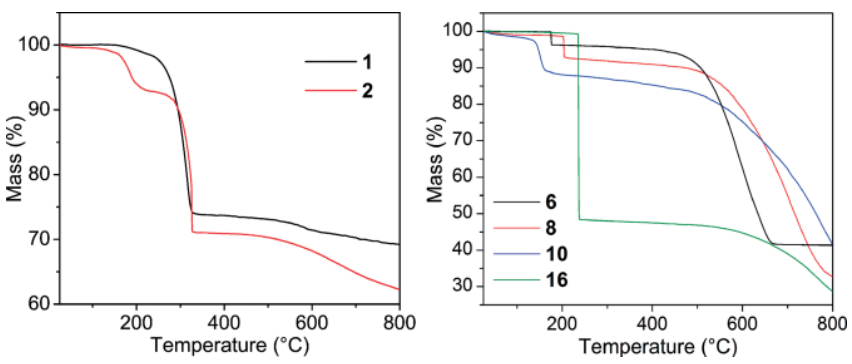

Figure 1. TGA decomposition profiles of $\mathbf{1}$ and $\mathbf{2}$ from ambient $-800{ }^{\circ} \mathrm{C}$ (left) TGA decomposition profiles of ethynylcuprates $\mathbf{6 , 8}, 10$ and 16 from ambient - $800{ }^{\circ} \mathrm{C}$ (right). Heating was performed at a rate of $10^{\circ} \mathrm{C} / \mathrm{min}$ under $\mathrm{N}_{2}$.

The TGA experiments revealed that both $\mathbf{1}$ and $\mathbf{2}$ underwent two main mass loss events upon heating from ambient temperature $\left(\approx 25^{\circ} \mathrm{C}\right)$ to $800{ }^{\circ} \mathrm{C}$. In $\mathbf{2}$, these two principle mass loss events were preceded by $\mathrm{a} \leq-0.5 \%$ change in mass up to $90{ }^{\circ} \mathrm{C}$ corresponding to expulsion of included $\mathrm{CH}_{2} \mathrm{Cl}_{2}$. In 1 , the first mass loss of $-1.3 \%$ occurred from $145-240{ }^{\circ} \mathrm{C}$, and in the case of 2 , the mass decreased by $-7 \%$ from $115-225^{\circ} \mathrm{C}$ due to initial partial sublimation of the material out of the crucible. ${ }^{[68]}$ The second and greatest change in mass of $-24 \%$ for 1 , and of $-22 \%$ for 2 occurred from $240-330^{\circ} \mathrm{C}$ due to chemical decomposition. In 2, this was found by differential scanning calorimetry (DSC) to be a strongly exothermic reaction involving the liberation of $275 \mathrm{~kJ} \mathrm{~mol}^{-1}$ of energy.

Thus, although $\mathbf{2}$ is rather more volatile than $\mathbf{1}$, they both exhibit similar thermal stabilities in the solid state, and are completely stable up to the maximum temperature employed for the solution cyclization reaction investigations $\left(170{ }^{\circ} \mathrm{C}\right.$, entries 18 and 30, Table 3). In a parallel experiment, 2 was refluxed in pyridine for 3 days in the presence of 3 equivalents of Cul under argon, and subsequently found to have undergone minimal decomposition, ${ }^{[69]}$ confirming that the product yield losses observed during the synthetic investigations were not due to thermal instabilities of $\mathbf{1}$ and $\mathbf{2}$ or to Cul mediated decompositions. 
The TGA heating profiles of the ethynylcuprates $\mathbf{6 , ~ 8 , ~} 10$ and 16 were also recorded, and are shown in Figure 1. Compounds 6 and 8 were found to undergo an initial explosive reaction at $175{ }^{\circ} \mathrm{C}$ ( $-4 \%$ mass) and $202{ }^{\circ} \mathrm{C}$ (-6\% mass) respectively. By contrast, 10 underwent a steady slight loss in mass up to $135^{\circ} \mathrm{C}$, then decomposed more smoothly over a temperature range of $135-180{ }^{\circ} \mathrm{C}(-10 \%$ mass). These comparatively small losses in mass are consistent with some type of thermal polymerization process. However, at $\geq 420{ }^{\circ} \mathrm{C}$ extensive chemical decomposition occurs with mass losses of $53 \%, 57 \%$ and $42 \%$ for $\mathbf{6 , 8}$ and 10 respectively, the last-mentioned decomposition of which was still underway at the heating limit of $800{ }^{\circ} \mathrm{C}$. Ethynylcuprate $\mathbf{1 6}$ was the most thermally stable of the series studied. However, it underwent a sudden explosive decomposition at $235{ }^{\circ} \mathrm{C}$ with a $51 \%$ mass loss.

Overall, the ethynylcuprate stabilities increase along the series: $\mathbf{1 0}<\mathbf{6}<\mathbf{8}<\mathbf{1 6}$, whereas the cyclization yields increased as follows from the corresponding ethynylcuprates: $10<\mathbf{1 6}<<$ $\mathbf{8}<\mathbf{6}$. Thus within the series studied, the least and most stable ethynylcuprates $\mathbf{1 0}$ and $\mathbf{1 6}$ gave the lowest cyclization yields ( $0 \% 3$ and $<1 \% 4$ respectively); a finding that is consistent with incompatibilities between the reaction cyclization temperature and the macrocycle/ethynylcuprate stability. For example, $\mathbf{1 0}$ is clearly of much lower thermal stability than $\mathbf{6}$ and $\mathbf{8}$, and is already undergoing some mass loss and internal chemical transformations well below $140{ }^{\circ} \mathrm{C}$, which was the temperature used for the unsuccessful synthesis of $\mathbf{3}$ (entries 19 and 20, Table 3). The enhanced thermal instability of $\mathbf{1 0}$ may therefore be a causative factor in its failure to cyclize to give $\mathbf{3}$. The much more stable $\mathbf{1 6}$ showed little propensity to react in pyridine at $140{ }^{\circ} \mathrm{C}$, whereas melting point studies clearly showed that 4 was already chemically transforming or decomposing at this temperature (see Supporting Information). This suggests that the elevated temperatures necessary for the cyclization of $\mathbf{1 6}$ result in the decomposition of $\mathbf{4}$ as it is formed.

\section{Summary of Factors Influencing the Cyclotrimerization Yields of 1-3}

Thus, the above investigations revealed a range of factors that negatively influence the cyclization reaction which may be summarized as follows: 1) stoichiometric excesses of $\mathrm{Cu}^{\prime} ; 2$ ) the replacement of $\mathrm{Cu}^{\prime}$ by $\mathrm{Ag}^{\prime}$; 3) the presence of strong donor ligands, e.g. $\mathrm{P}(t \mathrm{Bu})_{3}$ and $\mathrm{P}(n \mathrm{Oct})_{3}$, 4) conducting the thermal cyclization step in non- or poor solvents for the ethynylcuprate e.g. $p$-xylene and 1-methylmorpholine; 5) the presence of $\mathrm{H}_{2} \mathrm{O}$ in the thermal cyclization step; 6) reaction dilution; 7) heteroatoms adjacent to the coupling site, which may influence the thermal instability of the ethynylcuprate, ${ }^{[70]}$ and 8 ) the presence of structurally different ethynylcuprates such as intermediate $\mathbf{1 6}$ in the presence of $\mathbf{8}$. Overall, the stoichiometric reactions were insensitive to the anion (chloride vs. iodide), the ethynylcuprate ageing time and duration of thermal cyclization, as long as sufficient time was afforded for both processes, and that the latter was conducted within the temperature window of $120-170{ }^{\circ} \mathrm{C}$. $\mathrm{PPh}_{3}$ has a negligible effect on the cyclotrimerization yield or is even slightly detrimental to the cyclization in the case of the catalytic reactions.
"Fine tuning" solvent effects (pyridine vs. DMF) specific to base and 2-iodoarylethyne also appear to be operative. Thus in the case of the stoichiometric reactions, optimal yields for $\mathbf{1}$ are obtained with 2-iodoarylethyne/Cul/tBuOK in pyridine and 2-iodoarylethyne/Cul/ $\mathrm{K}_{2} \mathrm{CO}_{3}$ in DMF, and 2-iodoarylethyne/Cul/ tBuOK or $\mathrm{K}_{2} \mathrm{CO}_{3}$ in pyridine for 2 . In the catalytic generation of 1, optimal yields were obtained using 2-iodoarylethyne/Cul/ $\mathrm{K}_{2} \mathrm{CO}_{3}$ in DMF.

Lastly, the results in Table 4 clearly show that it is the $\mathrm{CO}_{3}{ }^{2-}$ and $\mathrm{HCO}_{3}{ }^{-}$anions that are responsible for catalytic recycling of the $\mathrm{Cu}^{\prime}$ in the cases where $\mathrm{Cul} / \mathrm{K}_{2} \mathrm{CO}_{3}$ was used as the metallating reagent, with the result that the reaction is self-catalytic with respect to $\mathrm{CuX}$ alone, i.e. without the need for ancillary ligands such as triphenylphosphine.

\section{Discussion of the Stephens-Castro Mediated Cyclotrimerization Reaction}

Although the reaction mechanism and identity of the organometallic species responsible for the cyclization pathway are currently unknown, examination of the crystal structures of ethynylcuprates show them to be highly aggregated polymers in the solid state, in the absence of additional ligands, which may exist as cyclic organometallic Cu'-ethyne bridged oligomers in the case of $[t \mathrm{BuC} \equiv \mathrm{CCu}]_{6}$ and $[t \mathrm{BuC} \equiv \mathrm{CCu}]_{8} \cdot{ }^{[59]}$ With additional ligands such as $\mathrm{PR}_{3}$, the non-polymeric structures $\left[\mathrm{Cu}_{2}-\right.$ $\left.\left(\mathrm{PPh}_{2} \mathrm{Me}\right)_{4}\left(\mu-\eta^{1}-\mathrm{C} \equiv \mathrm{CPh}\right)_{2}\right]^{[71]}$ and $\left[\mathrm{Cu}_{4}\left(\mathrm{PPh}_{3}\right)_{4}\left(\mu_{3}-\eta^{1}-\mathrm{C} \equiv \mathrm{CPh}\right)_{4}\right]^{[72-74]}$ are obtained, in the latter of which the ligands are arranged around a central $\mathrm{Cu}_{4}$-tetrahedron. Ethynylcuprates may also undergo structural rearrangements upon coordination to additional $\mathrm{Cu}^{\prime}$, either via ethyne-binding ${ }^{[75]}$ or coordination to orthopyridine nitrogens if present. ${ }^{[76]}$ These crystallographic reports raise the intriguing hypothesis that the formation of the dehydrotriaryl[12]annulene and higher cyclic oligomers may result from preorganized oligonuclear supramolecular aggregates/ clusters that assist in positioning the reactive groups into an arrangement favorable to thermal cyclization. Whereas excess $\mathrm{Cu}^{\prime}, \mathrm{PR}_{3}$, a pyridine nitrogen ortho- to the coupling site, and high dilution conditions, as well as the presence of structurally different ethynylcuprates, would be expected to cause breakup and rearrangement of such entities into structures unfavorable for cyclization coupling, i.e. consistent with the observed findings.

Heating the solid ethynylcuprate generated from the $t \mathrm{BuOCu}$ metallation in a non-solvent such as $p$-xylene causes suppression of cyclization showing that the cyclization reaction is not occurring in the solid state via reactions within the precipitated ethynylcuprate. ${ }^{[77]}$ Furthermore, $\mathbf{1}$ and $\mathbf{2}$ were obtained in reasonable yields from the $\mathrm{Cul} / \mathrm{K}_{2} \mathrm{CO}_{3}$ reactions performed in pyridine; reactions in which all components remained in solution. The organometallic species responsible for the cyclization is therefore a solution entity, and thus more likely to be oligomeric rather than polymeric in nature. ${ }^{[78]}$ No polymeric organic materials were identified during reaction workup. Apart from 1 and $\mathbf{2}$, tetramer macrocycles $\mathbf{4}$ and $\mathbf{1 7}$ were the only other products isolated from this reaction, consistent with a mechanism directing the reaction towards oligomerization rather than polymeri- 
zation, despite the relatively concentrated reaction conditions. ${ }^{[79]}$

In the case of the catalytic reactions resulting in $\mathbf{1}$, in which the $\mathrm{Cu}^{\prime}$ is recycled by the $\mathrm{CO}_{3}{ }^{2-}$ and $\mathrm{HCO}_{3}{ }^{-}$anions, it cannot be ruled out that these anions may be incorporated into and stabilize the organometallic species involved in the cyclization process. ${ }^{[80]}$

\section{Theoretical Investigations}

Based upon the known bonding modes of ethynylcuprates discussed above, we reasoned that if an aggregated solution entity is responsible for holding the ethynylcuprate monomers into an arrangement preorganized for cyclotrimerization, it would most likely incorporate three ethynylcopper(I) core units in close proximity.

Indeed, experimental evidence for such a core unit is to be found in the X-ray crystal structure of the tetranuclear cation $\left[\mathrm{Cu}_{4}\left\{\mathrm{P}\left(p-\mathrm{MeC}_{6} \mathrm{H}_{4}\right)_{3}\right\}_{4}\left(\mu_{3}-\eta^{1}, \eta^{1}, \eta^{2}-\mathrm{C} \equiv \mathrm{CR}\right)_{3}\right]^{+}$(where $\mathrm{R}=p$-MeO$\left.\mathrm{C}_{6} \mathrm{H}_{4}\right)$, which comprises a trimeric $\left[\mathrm{Cu}_{3}\left\{\mathrm{P}\left(p-\mathrm{MeC}_{6} \mathrm{H}_{4}\right)_{3}\right\}_{3}\left(\mu_{2}-\eta^{1}, \eta^{2}-\right.\right.$ $\left.\mathrm{C} \equiv \mathrm{CR})_{3}\right]$ ring capped on one face by a $\left[\mathrm{Cu}\left\{\mathrm{P}\left(p-\mathrm{MeC}_{6} \mathrm{H}_{4}\right)_{3}\right\}\right]^{+}$ unit. $^{[81]}$ This prompted us to perform DFT theoretical modeling on $\left[\mathrm{Cu}_{4}\left(\mathrm{C}_{5} \mathrm{H}_{5} \mathrm{~N}\right)_{4}\left(\mu_{3}-\eta^{1}, \eta^{1}, \eta^{2}-4-\mathrm{C} \equiv \mathrm{C}, 3-\mathrm{I}-\mathrm{C}_{5} \mathrm{H}_{3} \mathrm{~N}\right)_{3}\right]^{+}$, i.e. $\left[\mathbf{8}_{3} \mathrm{Cu}(\mathrm{Py})_{4}\right]^{+}$ (Figure 2), a hypothetical analogue of the abovementioned tetranuclear cationic complex in which the $p-\mathrm{MeOC}_{6} \mathrm{H}_{4}-\mathrm{C} \equiv \mathrm{CCu}$ and triarylphosphine ligands were replaced by respectively $\mathbf{8}$, the precursor of $\mathbf{2}$, and coordinating pyridines, as the reactions

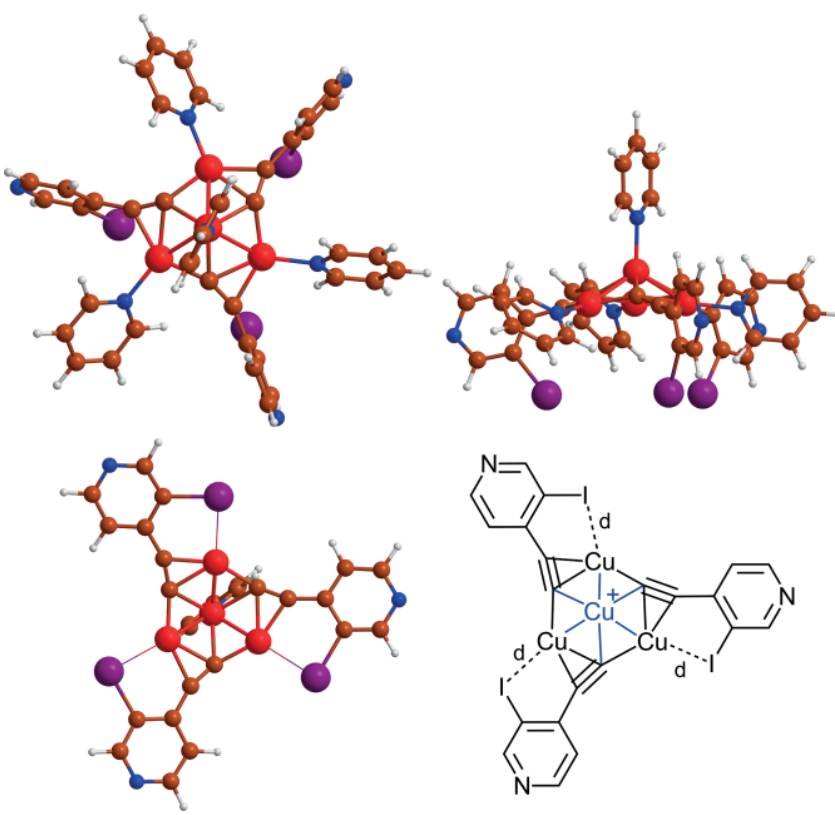

Figure 2. Density Functional Theory (DFT) molecular modeling at the B3LYP level of theory (employing the $6-31 \mathrm{G}^{*}$ and LANL2DZ $>\mathrm{Kr}$ basis sets) of $\left[\mathbf{8}_{3} \mathrm{Cu}(\mathrm{Py})_{4}\right]^{+}$and $\left[\mathbf{8}_{3} \mathrm{Cu}(\mathrm{Py})\right]^{+}$. Upper left: $\left[\mathbf{8}_{3} \mathrm{Cu}(\mathrm{Py})_{4}\right]^{+}$; view down axis of the capping $[\mathrm{Cu}(\mathrm{py})]^{+}$. Upper right: lateral view of $\left[\mathbf{8}_{3} \mathrm{Cu}(\mathrm{Py})_{4}\right]^{+}$. Lower left: Ventral view of $\left[\mathbf{8}_{3} \mathrm{Cu}(\mathrm{Py})\right]^{+}$with $\mathrm{Cu}$ and I atoms constrained at closest approach. Lower right: Schematic of computed model $\left[\mathbf{8}_{3} \mathrm{Cu}(\mathrm{Py})\right]^{+}$(pyridine removed for clarity) showing cuprophilic and Cu-ethyne bonding, where $\mathrm{d}=2.63 \AA$. Computed model color scheme C (brown), H (white), N (blue), Cu (red), I (purple). affording the highest yields of $\mathbf{2}$ were conducted in pyridine in the absence of triarylphosphines (Table 3 ).

In $\left[\mathbf{8}_{3} \mathrm{Cu}(\mathrm{Py})_{4}\right]^{+}$, the iodine atoms of each ethynylpyridine $\mathbf{8}$ are blocked from closest approach to the $\mathrm{Cu}$ atoms of each adjacent $\mathbf{8}$ by the coordinated pyridine ligands. We therefore applied two methods for calculating the distance of closest Cu...l approach. Firstly, the 3-iodopyridine rings of the calculated DFT model of $\left[\mathbf{8}_{3} \mathrm{Cu}(\mathrm{Py})_{4}\right]^{+}$were rotated about the pyridine N/C4 axis in order to orient each iodine closest to the nearest $\mathrm{Cu}$ atom. Secondly, we performed a DFT calculation on structure $\left[8_{3} \mathrm{Cu}(\mathrm{Py})\right]^{+}$in which the three meridionally coordinated pyridines were removed, and the iodines constrained to lie at closest approach to the nearest $\mathrm{Cu}$ atoms during minimization (Figure 2). From the rotation procedure performed on $\left[\mathbf{8}_{3} \mathrm{Cu}(\mathrm{Py})_{4}\right]^{+}$, we obtained an average Cu...। distance of closest approach of $2.95 \AA$. The DFT calculation on structure $\left[\mathbf{8}_{3} \mathrm{Cu}(\mathrm{Py})\right]^{+}$, afforded a Cu...l closest approach distance of $2.63 \AA$. The sum of the Van der Waals radii of atoms of $\mathrm{Cu}$ $(2.00 \AA)$ and iodine $(2.20 \AA)$ is $4.20 \AA$, and the sum of the ionic radii of $\mathrm{Cu}^{+}(0.46 \AA)$ and iodide $(2.20 \AA)$ is $2.66 \AA{ }^{\left[{ }^{[2]}\right]}$ The latter value being very close to the average $\mathrm{Cu}-\mathrm{I}$ bond length of $2.641 \AA$ in the X-ray crystal structure of $\left[\mathrm{Cu}_{2}(\mu-\mathrm{I})_{2} \mathrm{Py}_{4}\right]$ (Supporting Information). The shortest Cu...l distances calculated for both $\left[\mathbf{8}_{3} \mathrm{Cu}(\mathrm{Py})_{4}\right]^{+}$and $\left[\mathbf{8}_{3} \mathrm{Cu}(\mathrm{Py})\right]^{+}$are therefore within Van der Waals contact, and in the latter calculation, similar to the sum of ionic radii. Therefore from a theoretical perspective, the most proximal copper and iodine atoms in the cyclic tri-ethynylcopper(I) core of $\left[\mathbf{8}_{3} \mathrm{Cu}(\mathrm{Py})_{4}\right]^{+}$and $\left[\mathbf{8}_{3} \mathrm{Cu}(\mathrm{Py})\right]^{+}$do indeed lie in close enough proximity for possible chemical reaction with expulsion of Cul.

Pertinent to these investigations is the recently reported Stephens-Castro mediated cyclotrimerizations of $p-\mathrm{MeO}_{2} \mathrm{CPh}$ difunctionalized analogues of 6 possessing; 1 ) an ethynylcopper substituent as in 6, and; 2) an elongated $p$-ethynylphenylethynylcopper substituent in place of the shorter ethynylcopper substituent of $\mathbf{6}$, which afforded a $32 \%$ yield of dehydrotriaryl[12]annulene product in the former, and a $6 \%$ yield of cyclotrimer macrocyclic product in the latter reaction. ${ }^{[40]}$ These comparative cyclotrimerization reactions differ only in the length of the ethynylcopper substituent, yet result in a significant yield disparity. If preorganization into an entity such as for example one incorporating a tri-ethynylcopper(I) core unit discussed above, is operative in these reactions, the copper(I) and iodine reactive sites in the latter reaction would be positioned at a distance that is out of reach for an intra-aggregate cyclization, due to the increased length of the $p$-ethynylphenylethynylcopper substituents.

The feasibility that preorganized oligonuclear ethynylcuprate structures/aggregates may direct the Stephens-Castro reaction towards macrocyclization rather than polymerization, is therefore supported by theoretical investigations and by experimental yield differences such as that in the example discussed above. ${ }^{[40]}$ Future experimental investigations into the Stephens/ Castro mediated cyclization of oligonulear o-iodoarylethynylcuprates based upon $\left[\mathrm{Cu}_{4}\left\{\mathrm{P}\left(p-\mathrm{MeC}_{6} \mathrm{H}_{4}\right)_{3}\right\}_{4}\left(\mu_{3}-\eta^{1}, \eta^{1}, \eta^{2}-\mathrm{C} \equiv \mathrm{CR}\right)_{3}\right]^{+}$ (where $\mathrm{R}=\mathrm{o}-\mathrm{IC}_{6} \mathrm{H}_{4}$ ) for example, would therefore be of interest in order to throw more light on these considerations. 


\section{X-Ray Crystal Structure of Dehydrotetrapyrido[16]annulene 4}

Careful chromatographic purification of the combined yields of 2 and the following eluates yielded small quantities of a product that X-ray crystal structural analysis confirmed to be that of the macrocyclic tetramer 4 (Figure 3).
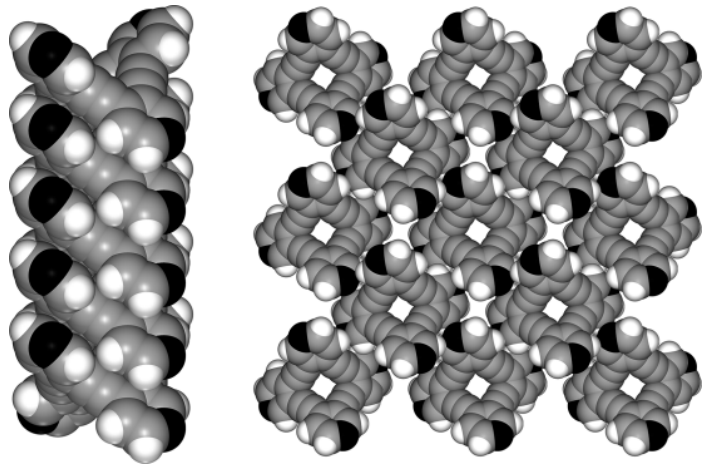

Figure 3. Space-filling representation of a single columnar stack of molecules of $\mathbf{4}$ that propagate along the c-axis; left. Space-filling representation of crystal packing of $\mathbf{4}$ in a-b plane; right.

Cycle 4 is a non-planar molecule which is folded along the axes that pass through the center of the cavity and bisect the pyridines on either side, to afford a V-shaped pocket of suitable dimensions for the inclusion of simple gases, metal ions and aromatic rings. The intramolecular $\mathrm{N}-\mathrm{N}$ distances of $\mathbf{4}$ are 8.827 $\AA$ between adjacent pyridines, and $9.860 \AA$ between pyridines lying on opposite sides of the cavity along the axes of folding. The diameter of the hole within the V-shaped pocket is $1.94 \times 2.45 \AA$, as defined by the inner Van der Waals surfaces. The cycle shows some degree of crystal packing-induced ring strain, as evidenced by the slight curvature of the alkynes towards the interior of the cavity as viewed down the c-axis. Further distortions are apparent when the macrocycle is viewed from its side along the $a-$ and b-axes, whereby pyridines positioned on opposite sides of the cycle are not in complete alignment as expected but slightly twisted relative to each other. However, the tetrameric structure of $\mathbf{4}$ is essentially identical to that of the hydrocarbon analogue 17 (Scheme 1), reported earlier by Youngs and co-workers. ${ }^{[83]}$

Depending upon the solvent of crystallization, 17 was isolated as two crystal polymorphs, which both comprised interlocked networks of cycles held together by various edge-toface and face-to-face aromatic $\pi-\pi$ interactions. In contrast, the molecules of $\mathbf{4}$ are stacked on top of each other into infinite tubular columns with intermolecular N-N distances of $4.664 \AA$ within each column. The columns in turn are packed into infinite parallel arrays which contact each other by inter-columnar $\mathrm{N} 1-\mathrm{H} 2$ hydrogen bonds of $2.710 \AA$ in length. ${ }^{[84]}$ Each macrocycle makes eight such hydrogen bonds with its nearest neighbors, resulting in a comparatively large number of such contacts that must play a significant role in the overall stabilization of the columnar packing. No solvent of crystallization is included in any part of the crystal lattice. Furthermore, all the pyridine nitrogens within each columnar stack directly overlay each other, with the result that the pyridine dipoles point in the same direction along each of the four edges of every column.
This situation would normally be expected to be repulsive and counterproductive to columnar stacking. Although the stacking of dehydrobenzo[ $n]$ annulenes and related macrocycles into tubular columnar arrays has been reported, they comprise entirely hydrocarbon structures with no potentially repulsive intermolecular effects. ${ }^{[85]}$ In $\mathbf{4}$ however, the overlying pyridine rings are slipped and offset with respect to each other such that only edge-to-edge $\pi-\pi$ contacts exist between the inner edge $\mathrm{C} 1$ and $\mathrm{C} 5$ and outer edge $\mathrm{C} 3$ and $\mathrm{N} 1$ atoms of each ring. This gives an infinite stepped ladder arrangement of interpyridine $\pi-\pi$ interactions, with $\mathrm{C} 1-\mathrm{C} 3$ and $\mathrm{C} 5-\mathrm{N} 1$ distances of 3.525 and $3.529 \AA$ respectively, ${ }^{[86]}$ that mitigates any repulsive dipole alignments that would arise if the center of the pyridine rings were more closely aligned.

\section{Conclusion}

Overall, our findings suggest that the expected stepwise reactions of molecules of ethynylcuprate $\mathbf{8}$ via intermediate $\mathbf{1 6}$ is not the principal reaction pathway leading to the formation of trimer $\mathbf{2}$ and tetramer macrocycle $\mathbf{4}$. The dominant cyclization process must therefore involve a more direct route from $\mathbf{8}$ to $\mathbf{2}$ and 4, which is suppressed by the presence of strong donor ligands such as $\mathrm{P}(n \mathrm{Oct})_{3}$, excess $\mathrm{Cu}^{\prime}$ and high dilution conditions. These findings, coupled with a cyclization yield dependency upon the structural reorganization of the ethynylcuprate observed for the 1:4, 8/tBuOCu reaction of entry 19, Table 2, is consistent with a pathway involving self-association of the ethynylcuprate monomers into structures preorganised for cyclization, and compatible with the known structural bonding modes reported for ethynylcuprates.

On the other hand, $\mathrm{PPh}_{3}$ was found to have a negligible effect upon the yields of $\mathbf{2}$, and $\mathbf{1}$ in both stoichiometric and catalytic modification of the Stephen-Castro reaction, contrary to the findings of lyoda and Miura et al. ${ }^{[25,65]}$ Our results therefore point to the $\mathrm{CO}_{3}{ }^{2-}$ anion, and not $\mathrm{PPh}_{3}$, as the agent primarily responsible for stabilizing the catalytic species and recycling the Cul. ${ }^{[87]}$

TGA studies revealed that $\mathbf{1}$ and $\mathbf{2}$ were stable to the temperatures employed for the cyclization reactions showing that yield variations were not originating from simple thermal decomposition of these products. Ethynylcuprate $\mathbf{1 0}$ was less stable than 6 and 8, suggesting that this may be a contributory factor to the failed generation of $\mathbf{3}$. Tetrameric by-product $\mathbf{4}$ was successfully isolated and crystallographically characterized, and shown to crystallize into a porous solid comprising tubular columns with parallel alignment.

Although the exact nature of the cyclotrimerization mechanism to afford dehydrotriaryl[12]annulenes remains unclear, our results point towards a process in which the nature of monomer ethynylcuprate aggregation in solution is influencing the success or failure of cyclization. A conclusion further supported by published X-ray crystallographic evidence and theoretical calculations described herein.

In the light of the continually expanding interest in dehydrotriaryl[12]annulenes, further investigations into the veracity of our hypothesis of ethynylcuprate preorganization will lead 
to an increased understanding of the Stephens-Castro reaction and contribute to the further development of dehydrotriaryl[12]annulenes and their higher cyclic oligomers as a wellspring of new materials.

Supporting Information. General experimental methods, General procedures for the syntheses of $\mathbf{1}$ and $\mathbf{2}$ and attempted synthesis of $\mathbf{3}$, isolation and purification of $\mathbf{4}$, preparation and characterization of $\mathbf{6 , 8}$ and $\mathbf{1 0}$ for the thermochemical and TEM studies. Physical Methods: UV/Vis, Luminescence Spectroscopic Infrared and TEM experimental, ${ }^{1} \mathrm{H}$ NMR spectra of $\mathbf{1}$ and $\mathbf{2}$, and ${ }^{1} \mathrm{H}$ and ${ }^{13} \mathrm{C}$ NMR spectra of 4 with peak assignments, General X-ray experimental, Crystallographic data, refinements and ORTEP representations for $\mathbf{4}$ and $\left[\mathrm{Cu}_{2}(\mu-\mathrm{I})_{2} \mathrm{Py}_{4}\right]$ with atom numbering, Calculated Structure Cartesian Coordinates of $\left[\mathbf{8}_{3} \mathrm{Cu}(\mathrm{Py})_{4}\right]^{+}$and $\left[\mathbf{8}_{3} \mathrm{Cu}(\mathrm{Py})\right]^{+}$, and references (continued).

CCDC 1951505 (for 4), 1951506 ffor $\left.\left[\mathrm{Cu}_{2}(\mu-\mathrm{I})_{2} \mathrm{Py}_{4}\right]\right\}$ contain the supplementary crystallographic data for this paper. These data can be obtained free of charge from The Cambridge Crystallographic Data Centre.

\section{Acknowledgments}

The Centre National de la Recherche Scientifique and the Institut Charles Sadron is acknowledged for financial support (P. N. W. B), and the Ministère de l'Enseignement Supérieur et de la Recherche for a PhD fellowship (A. A.). M. Legros and C. Saettel of the ICS are thanked for recording the TGA, and Dr B. Heinrich of the IPCMS, Strasbourg, is thanked for the DSC measurement, and Dr L. Allouche and B. Vincent of the Service RMN, GDS 3648-CNRS-UdS, are thanked for recording the ${ }^{13} \mathrm{C}$ NMR of 4, and Dr E. Wasielewski of the Cronenbourg NMR Core Facility, UMR 7042, for the 2-D correlation NMR of 13-15. Noémie Bourgeois of the Service d'analyses, de mesures physiques et de spectroscopie optique, Fédération de Chimie "Le Bel" - FR 2010 (Unistra - CNRS)

is thanked for the elemental analyses, and Corinne Bailly of the Service de Radiocristallographie, Fédération de Chimie "Le Bel" FR2010, for the Cambridge Crystallographic Database searches. Professor J. D. Wallace of Nottingham Trent University, G. Britain, is kindly thanked for insightfull discussions.

Keywords: Alkynes - Annulenes · Cross-coupling

Cuprates - Macrocycles

[1] Named variously in the literature as tribenzocyclyne and tribenzocyclotriyne (TBC), benzo[12]annulene, dehydrobenzo[12]annulene and trisdehydrotribenzo[12]annulene ([12]DBA), tribenzohexadehydro[12]annulene, hexadehydrotribenzo[12]annulene, hexadehydrotribenzo[a,e,i][12]annulene, 5,6,11,12,17,18-hexadehydrotribenzo[a,e,i]cyclododecene (TBC), 1,2:5,6:9,10-tribenzocyclododeca-1,5,9-triene-3,7,11-triyne and 1,2:5,6:9,10-tribenzo-3,7,11-tridehydro[12]annulene. For the sake of brevity and due to frequent use in the literature, this class of compound is herein referred to as dehydrotribenzo[12]annulene or the abbreviation [12]DBA.

[2] I. D. Campbell, G. Eglinton, W. Henderson, R. A. Raphael, J. Chem. Soc., Chem. Commun. 1966, 4, 87-89.

[3] H. A. Staab, F. Graf, Tetrahedron Lett. 1966, 7, 751-757.

[4] H. A. Staab, F. Graf, Chem. Ber. 1970, 103, 1107-1118.

[5] Y. Tobe, M. Sonoda in Modern Cyclophane Chemistry (Eds.: H. Hopf, R. Gleiter), Wiley-VCH, Weinheim, 2004, Ch. 1, pp. 1-40.
[6] H. Hopf, Classics in Hydrocarbon Chemistry: Syntheses, Concepts, Perspectives, Wiley-VCH, Weinheim, 2000, pp. 226-227.

[7] M. M. Haley, J. J. Pak, S. C. Brand in Topics in Current Chemistry: Carbon Rich Compounds II (Ed.: A. De Meijere), Springer-Verlag, 1999, vol. 201, pp. 81-130.

[8] J. Jusélius, D. Sundholm, Phys. Chem. Chem. Phys. 2001, 3, 2433-2437.

[9] A. J. Matzger, K. P. C. Vollhardt, Tetrahedron Lett. 1998, 39, 6791-6794.

[10] T. A. Schaub, M. Kivala in Metal-Catalyzed Cross-Coupling Reactions and More (Eds.: A. de Meijere, S. Bräse, M. Oestreich), Wiley-VCH, Weinheim, 2014, Ch. 9, pp. 665-667.

[11] R. D. Stephens, C. E. Castro, J. Org. Chem. 1963, 28, 3313-3315.

[12] K. Tahara, T. Yoshimura, M. Sonoda, Y. Tobe, R. V. Williams, J. Org. Chem. 2007, 72, 1437-1442.

[13] N. Narita, S. Nagai, S. Suzuki, Phys. Rev. B 2001, 64, 245408-1-245408-7.

[14] N. Narita, S. Nagai, S. Suzuki, K. Nakao, Phys. Rev. B 2000, 62, 1114611151.

[15] U. H. F. Bunz, Y. Rubin, Y. Tobe, Chem. Soc. Rev. 1999, 28, 107-119.

[16] N. Narita, S. Nagai, S. Suzuki, K. Nakao, Phys. Rev. B 1998, 58, 11009 11014.

[17] R. H. Baughman, H. Eckhardt, M. Kertesz, J. Chem. Phys. 1987, 87, 66876699.

[18] W. J. Youngs, C. A. Tessier, J. D. Bradshaw, Chem. Rev. 1999, 99, 31533180.

[19] J. D. Ferrara, A. A. Tanaka, C. Fierro, C. A. Tessier-Youngs, W. J. Youngs, Organometallics 1989, 8, 2089-2098.

[20] J. D. Ferrara, C. A. Tessier-Youngs, W. J. Youngs, J. Am. Chem. Soc. 1985, 107, 6719-6721.

[21] K. Tahara, Y. Yamamoto, D. E. Gross, H. Kozuma, Y. Arikuma, K. Ohta, Y. Koizumi, Y. Gao, Y. Shimizu, S. Seki, K. Kamada, J. S. Moore, Y. Tobe, Chem. Eur. J. 2013, 19, 11251-11260.

[22] K. Tahara, T. Yoshimura, M. Ohno, M. Sonoda, Y. Tobe, Chem. Lett. 2007, $36,838-839$.

[23] C. A. Johnson II, Y. Lu, M. M. Haley, Org. Lett. 2007, 9, 3725-3728.

[24] T. Yoshimura, A. Inaba, M. Sonoda, K. Tahara, Y. Tobe, R. V. Williams, Org. Lett. 2006, 8, 2933-2936.

[25] M. Iyoda, S. Sirinintasak, Y. Nishiyama, A. Vorasingha, F. Sultana, K. Nakao, Y. Kuwatani, H. Matsuyama, M. Yoshida, Y. Miyake, Synthesis 2004, 15271531.

[26] M. Sonoda, Y. Sakai, T. Yoshimura, Y. Tobe, K. Kamada, Chem. Lett. 2004, 33, 972-973.

[27] O. Š. Miljanić, K. P. C. Vollhardt, G. D. Whitener, Synlett 2003, 29-34.

[28] J. M. Kehoe, J. H. Kiley, J. J. English, C. A. Johnson, R. C. Petersen, M. M. Haley, Org. Lett. 2000, 2, 969-972.

[29] H. Nishide, M. Takahashi, J. Takashima, Y.-J. Pu, E. Tsuchida, J. Org. Chem. 1999, 64, 7375-7380.

[30] Y. J. Pu, M. Takahashi, E. Tsuchida, H. Nishide, Chem. Lett. 1999, 28, 161162.

[31] K. Kamada, L. Antonov, S. Yamada, K. Ohta, T. Yoshimura, K. Tahara, A. Inaba, M. Sonoda, Y. Tobe, ChemPhysChem 2007, 8, 2671-2677.

[32] S. H. Seo, T. V. Jones, H. Seyler, J. O. Peters, T. H. Kim, J. Y. Chang, G. N. Tew, J. Am. Chem. Soc. 2006, 128, 9264-9265.

[33] S. H. Seo, J. Y. Chang, G. N. Tew, Angew. Chem. Int. Ed. 2006, 45, 75267530; Angew. Chem. 2006, 118, 7688-7692.

[34] H. Shigemitsu, I. Hisaki, E. Kometani, D. Yasumiya, Y. Sakamoto, K. Osaka, T. S. Thakur, A. Saeki, S. Seki, F. Kimura, T. Kimura, N. Tohnai, M. Miyata, Chem. Eur. J. 2013, 19, 15366-15377.

[35] N. Saito, R. Terakawa, M. Yamaguchi, Chem. Eur. J. 2014, 20, 5601-5607.

[36] I. Hisaki, H. Senga, H. Shigemitsu, N. Tohnai, M. Miyata, Chem. Eur. J. 2011, 17, 14348-14353.

[37] K. Tahara, T. Fujita, M. Sonoda, M. Shiro, Y. Tobe, J. Am. Chem. Soc. 2008, 130, 14339-14345.

[38] M. Kiguchi, K. Tahara, Y. Takahashi, K. Hasui, Y. Tobe, Chem. Lett. 2010, 39, 788-789.

[39] I. Hisaki, Y. Sakamoto, H. Shigemitsu, N. Tohnai, M. Miyata, S. Seki, A. Saeki, S. Tagawa, Chem. Eur. J. 2008, 14, 4178-4187.

[40] I. Hisaki, S. Nakagawa, N. Ikenaka, Y. Imamura, M. Katouda, M. Tashiro, H. Tsuchida, T. Ogoshi, H. Sato, N. Tohnai, M. Miyata, J. Am. Chem. Soc. 2016, 138, 6617-6628.

[41] I. Hisaki, S. Nakagawa, Y. Suzuki, N. Tohnai, Chem. Lett. 2018, 47, $1143-$ 1146. 
[42] D. Zhang, C. A. Tessier, W. J. Youngs, Chem. Mater. 1999, 11, 3050-3057.

[43] D. Solooki, J. D. Ferrara, D. Malaba, J. D. Bradshaw, C. A. Tessier, W. J. Youngs, Inorg. Synth. 1997, 31, 122-128.

[44] J. D. Kinder, C. A. Tessier, W. J. Youngs, Synlett 1993, 149-150.

[45] K. Tahara, S. Furukawa, H. Uji-i, T. Uchino, T. Ichikawa, J. Zhang, W. Mamdouh, M. Sonoda, F. C. De Schryver, S. De Feyter, Y. Tobe, J. Am. Chem. Soc. 2006, 128, 16613-16625.

[46] S. Takahashi, Y. Kuroyama, K. Sonogashira, N. Hagihara, Synthesis 1980, 627-630.

[47] K. Sonogashira, Y. Tohda, N. Hagihara, Tetrahedron Lett. 1975, 16, 44674470

[48] K. Tahara, S. Lei, D. Mössinger, H. Kozuma, K. Inukai, M. Van der Auweraer, F. C. De Schryver, S. Höger, Y. Tobe, S. De Feyter, Chem. Commun. 2008, 3897-3899.

[49] K. Tahara, H. Yamaga, E. Ghijsens, K. Inukai, J. Adisoejoso, M. O. Blunt, S. De Feyter, Y. Tobe, Nat. Chem. 2011, 3, 714-719.

[50] T. Nishinaga, H. Nakayama, N. Nodera, K. Komatsu, Tetrahedron Lett. $1998,39,7139-7142$.

[51] C. Huynh, G. Linstrumelle, Tetrahedron 1988, 44, 6337-6344.

[52] Y. Li, J. Zhang, W. Wang, Q. Miao, X. She, X. Pan, J. Org. Chem. 2005, 70, 3285-3287.

[53] M. Csékei, Z. Novák, A. Kotschy, Tetrahedron 2008, 64, 975-982.

[54] H. Yang, Y. Du, S. Wan, G. D. Trahan, Y. Jin, W. Zhang, Chem. Sci. 2015, 6, 4049-4053.

[55] O. Š. Miljanić, K. P. C. Vollhardt, G. D. Whitener, Synlett 2003, 1, 29-34.

[56] J. W. Barton, M. K. Shepherd, Tetrahedron Lett. 1984, 25, 4967-4970.

[57] M. lyoda, A. Vorasingha, Y. Kuwatani, M. Yoshida, Tetrahedron Lett. 1998, 39, 4701-4704.

[58] P. N. W. Baxter, R. D.-Youcef, J. Org. Chem. 2005, 70, 4935-4953.

[59] S. S. Y. Chui, M. F. Y. Ng, C.-M. Che, Chem. Eur. J. 2005, 11, 1739-1749 and references cited therein.

[60] In this case (entry 3, Table 2), the increase in yield of $\mathbf{2}$ upon moderate dilution of the reaction is consistent with a dilution-induced dissociation of $\mathrm{Cu}^{\prime}$ from the reactive species, thereby reversing the negative effect of excess $\mathrm{Cu}^{\prime}$, discussed later.

[61] This process is indicated visually by the initial production of a dark brown solution, in the presence of excess $\mathrm{CuX}$ and $t \mathrm{BuOCu}$ (entries 5 , $18,20,21$; Table 2), which result in zero yields of $\mathbf{2}$ after heating. However, with longer ageing times prior to heating, the normally observed red precipitate of sparingly soluble $\mathbf{8}$ reappears, and subsequent heating affords improved yields of $\mathbf{2}$ (entries 14-16 and 19; Table 2). It must be noted however that subsequent experiments (entry 17, Table 3) showed that the reactive precursor leading to $\mathbf{2}$ was a solution species rather than the precipitate itself.

[62] After removal of the reaction solvent in the initial phase of workup, the residue was partitioned between aqueous $\mathrm{KCN}$ and $\mathrm{CH}_{2} \mathrm{Cl}_{2}$, during which 8 if present, is demetallated to $\mathbf{7}$. The combined organic extracts were then dried, and the solvent distilled off at ambient temperature. Extraction of the residue with $n$-pentane selectively dissolves out the $\mathbf{7}$, which can be subsequently isolated and weighed in order to determine the actual yield of $\mathbf{2}$ based upon $\mathbf{7}$ consumed.

[63] In the systems employing 1:1 to 1:3 stoichiometric ratios of 7/tBuOCu, the 8 always appears during ambient temperature ageing as a red or red-orange precipitate in pyridine, 4-tBu-pyridine, $\mathrm{PhCN}$ and DMF, and as an orange solid in 1-methyl-morpholine and $p$-xylene. During subsequent heating, the precipitate gradually changes color to black.

[64] Excepting entry 23, the [5], [7] and [9] $=6 \times 10^{-2} \mathrm{~mol} \mathrm{~L}^{-1}$ in all other entries of Table 3. By comparison, the [7] and [5] $=3 \times 10^{-3} \mathrm{~mol} \mathrm{~L}^{-1}$ in the medium dilution reactions of entry 10 of Table 2 and that of entry 23 of Table 3 respectively.

[65] K. Okuro, M. Furuune, M. Enna, M. Miura, M. Nomura, J. Org. Chem. 1993, $58,4716-4721$.

[66] If the reactions in Table 4 were stoichiometrically quantitative but entirely non-catalytic, the maximum yield of $\mathbf{1}$ that could be obtained from $0.3 \mathrm{~mol}$ Cul would be $29.3 \%$. As none of the yields of the reactions described in entries 10-13 of Table 4 exceed this value, the $t \mathrm{BuOK} / \mathrm{Cu}$ mediated cyclizations cannot be unambiguously shown to be catalytic.

[67] It may be noted that in the catalytic reactions performed in pyridine, the yields of $\mathbf{1}$ were marginally higher when the cyclizations were performed in the presence of $\mathrm{PPh}_{3}$ (cf. entries 8/9 and entries 12/13,
Table 4). However these small yield differences (3\% and $1 \%$ respectively) may lie within the natural yield variation of each reaction, so that a slight positive phosphine effect cannot yet be unambiguously ascertained for these reactions.

[68] The onset and termination of the two principal mass loss processes occurred $15-20^{\circ} \mathrm{C}$ lower when the TGA heating was performed at $2{ }^{\circ} \mathrm{C} / \mathrm{min}$, compared to $10{ }^{\circ} \mathrm{C} / \mathrm{min}$. The TGA mass loss profiles were independent of whether argon or nitrogen was employed as the carrier gas.

[69] As determined by ${ }^{1} \mathrm{H}$ NMR integrations of the macrocycle proton resonances compared to that of the internal $\mathrm{CHCl}_{3}$ in the $\mathrm{CDCl}_{3}$ solvent, at a $1 \times 10^{-2} \mathrm{~mol} \mathrm{~L}^{-1}$ [2] before and after reaction. After refluxing with $\mathrm{Cul}$ and removal of the pyridine by warming under reduced pressure, the $\mathbf{2}$ was decomplexed from the Cul by extraction between $\mathrm{CH}_{2} \mathrm{Cl}_{2}$ and $10 \%$ aq. KCN.

[70] This effect mirrors the Stephens/Castro cyclotrimerization reactivity pattern of ortho-ethynyliodothiophenes: D. Solooki, V. O. Kennedy, C. A. Tessier, W. J. Youngs, Synlett 1990, 427-428.

[71] V. W.-W. Yam, W.-K. Lee, K.-K. Cheung, H.-K. Lee, W.-P. Leung, J. Chem. Soc., Dalton Trans. 1996, 2889-2891.

[72] V. W.-W. Yam, W.-K. Lee, K.-K. Cheung, J. Chem. Soc., Dalton Trans. 1996, 2335-2339.

[73] M. P. Gamasa, J. Gimeno, E. Lastra, X. Solans, J. Organomet. Chem. 1988 $346,277-286$

[74] L. Naldini, F. Demartin, M. Manassero, M. Sansoni, G. Rassu, M. A. Zoroddu, J. Organomet. Chem. 1985, 279, C42-C44.

[75] For a crystallographically characterized $\mathrm{Cu}^{\prime}$-phenylacetylide complex, $\left[\mathrm{Cu}_{3}\left(\mu_{2}-\mathrm{dppm}\right)_{3}\left(\mu_{3}, \eta^{1}-\mathrm{C} \equiv \mathrm{CPh}\right)_{2}\right] \mathrm{PF}_{6}$, incorporating extra $\mathrm{Cu}^{\prime}$, see: V. W.-W. Yam, W.-K. Lee, T.-F. Lai, Organometallics 1993, 12, 2383-2387.

[76] M. C. Blanco, J. Camara, M. C. Gimeno, P. G. Jones, A. Laguna, J. M. Lopezde-Luzuriaga, M. E. Olmos, M. D. Villacampa, Organometallics 2012, 31, 2597-2605.

[77] All reaction components remained in solution throughout the course of the ageing time and heating stage of the medium dilution reaction of entry 23 of Table 3 . The absence of ethynylcuprate precipitates that are normally observed for the more concentrated reactions involving $t \mathrm{BuOCu}$ as metallating agent, reinforces the conclusion that the cyclization step occurs by way of a non-polymeric solution species.

[78] Attempts were also undertaken to characterize some of the entities produced upon ambient temperature ageing of the reactions described in entries 6 and 13 of Table 3, both by crystallization of solution species from the reaction medium via diethyl ether vapor diffusion and by ESI and MALDI mass spectral analyses. However, the crystallization experiments yielded only $\left[\mathrm{Cu}_{2}(\mu-1)_{2} \mathrm{Py}_{4}\right]$, which was identified by X-ray crystallography and found to have a different packing to that described in G. C. Dyason, L. M. Engelhardt, P. C. Healy, A. H. White, Aust. J. Chem. 1984, 37, 2201-2205. The structural details of this modification are therefore included in the Supporting Information. Furthermore, the peaks in the mass spectra of the reaction solutions did not correspond to any identifiable $\mathrm{Cu}^{\prime}$ containing species.

[79] The cyclic tetramers $\mathbf{4}$ and $\mathbf{1 7}$ were searched for in all table entries, but were found to be produced in only very low yields, contributing little to the total mass balance of each reaction. For example, isolation of a multimilligram quantity of cycle $\mathbf{4}$ was only possible upon combination of all the chromatographic eluates containing traces of this compound from all the table entries affording $\mathbf{2}$, as detailed in the Supporting Information. Unidentified by-products were also observed in the ${ }^{1} \mathrm{H}$ NMRs of the crude reaction products, as well as insoluble black solids that sometimes hampered the solvent extractive stage of workups, but all were formed in only very small/trace amounts. However, we cannot rule out the possibility of competing dehalogenation reaction pathways that would afford volatile products, lost upon workup. Starting $\mathbf{7}$ was isolated only in the cases of entries 3,11 and 17 of Table 3 . In all reactions, the yields of $\mathbf{1}$ and $\mathbf{2}$ were based upon $\mathbf{5}$ and $\mathbf{7}$ consumed.

[80] The coordination complexes $\left(\mathrm{PPh}_{3}\right)_{2} \mathrm{Cu}_{2} \mathrm{CO}_{3}$ and $\left[\left(\mathrm{PPh}_{3}\right)_{2} \mathrm{CuCO}_{3} \mathrm{H}\right]_{2}$ have been crystallographically characterized, see: D. J. Darensbourg, M. W. Holtcamp, B. Khandelwal, J. H. Reibenspies, Inorg. Chem. 1995, 34, 53905394.

[81] C.-L. Chan, K.-L. Cheung, W. H. Lam, E. C.-C. Cheng, N. Zhu, S. W.-K. Choi, V. W.-W. Yam, Chem. Asian J. 2006, 1-2, 273-286.

[82] S. S. Batsanov, Inorg. Mater. 2001, 37, 871-885. 
[83] D. Solooki, J. D. Bradshaw, C. A. Tessier, W. J. Youngs, R. F. See, M. Churchill, J. D. Ferrara, J. Organomet. Chem. 1994, 470, 231-236.

[84] The $\mathrm{H} 2$ hydrogens are those meta- to pyridine nitrogens.

[85] See for example: M. Suzuki, A. Comito, S. I. Khan, Y. Rubin, Org. Lett. 2010, 12, 2346-2349.

[86] These distances lie within the accepted range for aromatic $\pi-\pi$ interactions of 3.4-4.8 A. See for example, C. A. Hunter, J. Singh, J. M. Thornton, J. Mol. Biol. 1991, 218, 837-846.
[87] The positive effect of $\mathrm{PPh}_{3}$ on the yields of the Stephens-Castro reaction reported by Miura et al., in reference [65] may in fact originate from a rate enhancement rather than a yield enhancement. The $5 \mathrm{~h}$ reaction time stated for the reactions in Table 1 of Miura et al., may have been insufficient for the reaction without $\mathrm{PPh}_{3}$ to go to completion, consistent with the low yield of diphenylacetylene coupling product reported for this entry.

Received: July 19, 2019 